\title{
LA INTEGRACIÓN DEL MEDIO FÍSICO EN LA GESTIÓN INTEGRADA DE RECURSOS HÍDRICOS DE LA MARINA BAJA (ALICANTE)
}

\author{
Teresa Torregrosa Martí \\ Martín Sevilla Jiménez \\ Departamento de Análisis Económico Aplicado \\ Universidad de Alicante
}

\section{RESUMEN}

La integración del medio natural o físico toma como punto de partida el ciclo hidrológico, y se basa en la integración de los recursos tierra y agua, en la calidad y cantidad de los recursos hídricos, en la integración de las aguas superficiales y subterráneas junto con recursos alternativos y, por último, en las interrelaciones entre actividades agrícolas, bosques y procesos de urbanización, con los impactos hídricos y de calidad asociados. Y es aquí donde centramos el trabajo presentado: la delimitación del sistema físico en la comarca de la Marina Baja y su adecuación a los requerimientos de una gestión integrada de recursos hídricos. Desde el punto de vista del medio físico, consideramos que existe una integración física de recursos hídricos cuando los recursos son utilizados de manera complementaria, las demandas identificables y acordes a los recursos disponibles, con cierto margen de maniobra y garantizado todo ello por un marco legal que asegure la obtención de recursos, en cantidad y calidad óptimas para satisfacer las demandas consolidadas y previstas de manera sostenible.

Palabras Clave: medio físico, gestión integrada de recursos hídricos, uso urbano, uso agrícola, competencia de usos. 


\begin{abstract}
The collective use of resources requires the planned and coordinated use of a variety of sources. The proportions in which the quantities of water from one source or another are combined will depend on the stage of the natural water cycle, the current reserves within the system, both surface water and that stored in aquifers, the quality available and, above all, the objectives set for the exploitation of the system. And here is where we focused the presented paper, the delimitation of the physical system in Marina Baja District. We believe that physical integration of water resources occurs when resources are used in a complementary manner, with demand which is both identifiable and in keeping with available resources, and with a certain margin for manoeuvre, all guaranteed by a legal framework which assures the securing of resources at optimal levels of quantity and quality in order to satisfy consolidated and forecast demand in a sustainable manner
\end{abstract}

Keywords: Physical system, integrated water resource management, urban water use, agricultural water use, use competence.

\title{
1. INTRODUCCIÓN
}

El estudio de las características del sistema de funcionamiento de las variables que afectan a las demandas de agua y a las posibilidades de obtención de los recursos disponibles ha sido tradicionalmente enfocado como un problema físico en las áreas donde se ha aplicado, tratando de identificar los factores que influyen en los consumos a través del tiempo y las distintas fuentes, para afrontar los mismos en unas delimitaciones territoriales específicas. La existencia de sistemas de aprovechamiento en los que el espacio a aplicar los balances hídricos ha podido ser ampliado, tanto a través de las delimitaciones de las confederaciones hidrográficas, como de los trasvases de aguas inter o intracuencas, no ha sido en principio determinante a la hora de la búsqueda de soluciones más o menos racionales de los aprovechamientos disponibles en determinados espacios. La sostenibilidad de estos espacios depende tanto de la evolución de las demandas y sus expectativas de crecimiento como de las posibilidades y costes para obtener recursos a menor escala, esto es, dentro del propio sistema de explotación. Estos hechos que tradicionalmente se han resuelto en España con el predominio de los derechos tradicionales sobre las aguas que han ejercido especialmente las comunidades de regantes, auténticas detentadoras de la mayoría de los recursos existentes a través de las concesiones y derechos consuetudinarios, en los últimos años se han visto puestas en cuestión. Las demandas de nuevos agentes económicos y sociales y la aparición de nuevas fuentes de suministro, especialmente 
aguas subterráneas y las procedentes de la desalación y reutilización, han puesto el énfasis en la gestión sostenible de los recursos como el método más adecuado para intentar colmar las aspiraciones de todos los agentes. La comarca de la Marina Baja, en la zona costera de Alicante, es un buen ejemplo de esta situación.

Hemos pretendido adecuar el análisis presentado a un modelo de Gestión Integrada de Recursos Hídricos (en adelante, GIRH). El modelo de GIRH es recomendado desde la mayor parte de los organismos internacionales como válido a la hora de mejorar la gestión de los recursos hídricos desde una perspectiva de sistemas sostenible, integrada, holística y multidisciplinar. La adaptación al caso concreto de estudio nos ha, llevado en trabajos recientes, a reducir este marco teórico a la integración de tres sistemas que hemos identificado claramente en la Marina Baja: el sistema físico o medio físico, el sistema socioeconómico y el sistema político-institucional. La comarca de la Marina Baja, en el Sureste peninsular, representa unas particularidades físicas, económicas y sociales, que la convierten en el escenario idóneo para el análisis de prácticas de utilización conjunta de recursos. El trabajo presentado analiza la integración concreta del medio físico en la zona de estudio y su adecuación a los condicionantes de la aplicación de una GIRH.

La definición más aceptada y citada es la que ofrece la Global Water Partnership (GWP), que establece que la GIRH «es un proceso que promueve el desarrollo coordinado y la gestión del agua, la tierra y los recursos relacionados, para maximizar el resultado económico y el bienestar social de una manera equitativa, sin comprometer la sostenibilidad de los ecosistemas vitales» (GWP, 2000). La GIRH se basa en lo que conocemos como perspectiva de sistemas. Un enfoque de sistemas consiste en la aplicación de metodologías específicas a sistemas o entidades complejas, para poder hacer frente a problemas del mundo real. Adaptando el modelo propuesto por Ohlson (1999), consideramos que la aplicación del modelo de GIRH a nuestro caso concreto de estudio, la comarca de la Marina Baja (Alicante) requiere la identificación e integración de tres sistemas: el sistema o "medio" físico, el sistema político-institucional y el sistema socioeconómico. La integración del sistema natural o físico toma como punto de partida el ciclo hidrológico, y se basa en la integración de los recursos tierra y agua, en la calidad y cantidad de los recursos hídricos, en la integración de las aguas superficiales y subterráneas junto con recursos alternativos y, por último, en las interrelaciones entre actividades agrícolas, bosques y procesos de urbanización, con los impactos hídricos y de calidad asociados (Jonch-Clausen y Fugl, 2001). Y es aquí donde centramos el trabajo presentado: la delimitación del medio físico en la comarca de la Marina Baja y su adecuación a los requerimientos de una GIRH. Desde el punto de vista del medio físico, consideramos que existe una integración física de recursos hídricos cuando los recursos son utilizados de 
manera complementaria, las demandas identificables y acordes a los recursos disponibles, con cierto margen de maniobra y garantizado todo ello por un marco legal que asegure la obtención de recursos, en cantidad y calidad óptimas para satisfacer las demandas consolidadas y previstas de manera sostenible.

La gestión integrada de recursos con una marcada utilización conjunta responde más a causas del azar que a una planificación programada con antelación. En zonas como el Campo de Tarragona y básicamente la comarca de la Marina Baja, dichas actuaciones han sido impulsadas en su mayoría a iniciativa de los usuarios, bien a escala individual u organizados en comunidades y asociaciones de regantes, en zonas donde la competencia por los recursos disponibles es elevada.

\section{EL MEDIO FÍSICO EN LA COMARCA DE LA MARINA BAJA}

Una correcta aplicación de la GIRH requiere conocer con detalle los datos referentes al área de estudio, los recursos existentes, así como una identificación de los usos y demandas. Es lo que hemos dado en denominar el medio físico.

La comarca de la Marina Baja es uno de los nueve sistemas de explotación en que quedó dividida la cuenca hidrográfica del Júcar a raíz de la aprobación del Plan Hidrológico de Cuenca del Júcar ${ }^{1}$ (en adelante, PHCJ) en 1997. Se sitúa en la provincia de Alicante y comprende las cuencas propias de los ríos Algar y Amadorio, y las subcuencas litorales comprendidas entre el río Algar y el límite Sur del término municipal de Villajoyosa.

Formada por diecinueve municipios que ocupan una extensión de $624,9 \mathrm{~km}^{22}$, desde el punto de vista geográfico, la comarca puede dividirse en dos: un interior montañoso, donde se localizan las sierras más altas de la provincia -Aitana y Puig Campana-, así como la Sierra de Bernia y el Cabeçò d'Or, y una llanura costera. La Sierra de Aitana, con 1.558 m, pertenece al conjunto estructural de la Cordillera Bética en su extremo más oriental dentro de la Península Ibérica y constituye el punto más elevado de la provincia de Alicante. El Puig Campana, de $1.410 \mathrm{~m}$, es el segundo punto más alto de la provincia y montaña emblemática de Finestrat, localidad en la que se encuentra. La Sierra de Bernia se extiende perpendicular a la costa, entre Callosa d'En Sarrià y la Punta de Toix, y alcanza los 1.129 m. La llanura costera, con menores oscilaciones térmicas, está formada por kilómetros de acantilados y playas que facilitan el desarrollo de una de las actividades principales de la comarca: el turismo.

1 Artículo 2 del Plan Hidrológico de Cuenca del Júcar. Tomo I, Normativa. CHJ (1999)

2 Dato obtenido a partir de las fichas municipales del Instituto Valenciano de Estadística, actualizadas a fecha de 2005. 
En el sistema Marina Baja el clima es mediterráneo semiárido. La temperatura media anual ronda los $14,4^{\circ} \mathrm{C}$, pero con agudos contrastes climáticos ya que Benidorm, orientada al mediodía y protegida de los vientos del Norte por las sierras que la rodean, tiene una temperatura media anual de $19^{\circ} \mathrm{C}$, mientras que los valles de Guadalest o de Tárbena tienen temperaturas mucho más extremas.

La evolución pluviométrica anual presenta dos sectores diferenciados al igual que casi todas las características físicas de la misma. Por un lado, se encuentran las cuencas de los ríos Guadalest y Algar, donde la pluviometría es relativamente elevada aunque irregular, situándose el valor anual medio en los 645 y $598 \mathrm{l} / \mathrm{m}^{2}$ respectivamente ${ }^{3}$. Por otro lado, los valores en la cuenca del Amadorio, si bien son más regulares, son sensiblemente inferiores, en torno a los $277 \mathrm{l} / \mathrm{m}^{2}$ (CAMB, 2005).

\subsection{Recursos disponibles convencionales. Aguas superficiales y subterráneas}

En la comarca de la Marina Baja -sistema de explotación que cuenta con los menores recursos superficiales dentro de la Demarcación Hidrográfica del Júcar- la mayoría de los recursos son de procedencia subterránea. Los datos finales dependen de la fuente consultada. Así, los publicados por la CHJ (2007) y la Generalitat Valenciana (2002) afirman que la Marina Baja dispone de unos $45 \mathrm{hm}^{3} /$ año, de los cuales 26 son aportes subterráneos, $7 \mathrm{hm}^{3}$ de aguas superficiales y unos $12 \mathrm{hm}^{3}$ procedentes de la reutilización de aguas residuales depuradas. Datos más recientes facilitados directamente por el CAMB muestran una situación radicalmente distinta: la comarca de la Marina Baja contaba en 2005 (CAMB, 2006) con unos recursos superficiales del orden de los $20 \mathrm{hm}^{3}$, y unos de $40 \mathrm{hm}^{3}$ de procedencia subterránea. Si a estos caudales añadimos los almacenados en los embalses de Guadalest y Amadorio, arrojan un total de recursos disponibles en el sistema de más de $70 \mathrm{hm}^{3}$, muy superiores a los que señala la Generalitat Valenciana (2002).

Los recursos superficiales provienen principalmente de los ríos Algar, Guadalest, Sella y Amadorio. La cuenca del Algar, de 93'7 km², se localiza en la parte más occidental de la Sierra de Bernia, donde se sitúan las fuentes del Algar. Aguas abajo confluye con el río Bolulla y, posteriormente, recibe los aportes del Guadalest cerca del municipio de Polop, desembocando en el Mediterráneo en las proximidades del municipio de Altea. El río Guadalest tiene una cuenca de $112,5 \mathrm{~km}^{2}$. Nace en la Sierra de Serrella y discurre

3 Dentro de la cuenca Algar-Guadalest, la parte formada por los ríos Algar y Bolulla tiene un índice pluviométrico anual por encima de los $1.000 \mathrm{l} / \mathrm{m}^{2}$. 
paralelamente a la Sierra de Aixorta. En la parte alta del río se emplaza uno de los dos embalses principales del sistema de explotación: el embalse de Guadalest. El río Amadorio, con una cuenca de $205 \mathrm{~km}^{2}$, nace en la Sierra de Retamar y, aguas arriba, entre los términos municipales de Orcheta y Villajoyosa, se sitúa en embalse al que da nombre, el de mayor capacidad de la comarca. Aguas abajo, recibe los aportes del río Sella, prolongándose hasta Villajoyosa, donde desemboca.

La identificación de los recursos subterráneos disponibles requiere de algunas especificaciones previas. A raíz de la aprobación de la Directiva Marco de Aguas (en adelante, DMA), los estados miembros se comprometieron a llevar a cabo una caracterización inicial de todas las masas de agua, tanto superficial como subterránea. Atendiendo a lo dictaminado por la DMA, en la Confederación Hidrográfica del Júcar se han definido las masas de agua subterránea partiendo de las Unidades Hidrogeológicas (en adelante, UHG) especificadas en los diferentes planes de cuenca (CHJ, 2005a). Los criterios para establecer una y otra distinción no son plenamente coincidentes ${ }^{4}$, por lo que mientras que el PHCJ divide la demarcación en $52 \mathrm{UHG}^{5}$, el número total de masas de agua subterráneas identificadas es de $81^{6}$. Dado que los datos de que disponemos se refieren principalmente a UHG y que, además, las tres UHG que afectan al sistema de explotación Marina Baja coinciden con su correspondiente denominación como masa de agua subterránea, es indiferente utilizar uno u otro concepto en nuestro caso, por tanto, utilizaremos el de UHG.

El artículo 12 del PHCJ establece la adscripción de las UHG a cada uno de los sistemas de explotación de la demarcación. Las que se adscriben al sistema de la Marina Baja, aunque no de manera exclusiva, son la número 8.45 Sierra Aitana, la 8.46 Serrella-Aixorta-Algar y la 8.48 Orcheta.

La UHG de Sierra Aitana se alimenta por infiltración pluviométrica y su descarga es a través de manantiales cercanos a la Nucía y extracciones por bombeo. La UHG 8.46, la de Serrella-Aixorta-Algar, no es exclusiva del sistema de explotación Marina Baja, sino compartida con el sistema Serpis y el de

4 Para ver la definición que utiliza el Ministerio de Medio Ambiente sobre las masas de agua subterráneas, ver el documento Estudio Inicial para la identificación y caracterización de las masas de agua subterránea de las cuencas intercomunitarias (MIMAM, 2004).

5 Artículo 11 del Tomo I del Plan Hidrológico de Cuenca del Júcar, Normativa.

6 Para un mayor detalle de las 81 masas de agua, ver Delimitación y caracterización de los acuíferos en las UHG de la Confederación Hidrográfica del Júcar. Estimación del recurso disponible (CHJ, 2005), citado en CHJ (2005a). 
la Marina Alta ${ }^{7}$. La alimentación es por agua de lluvia y la descarga se produce de forma natural mediante los manantiales de Fuente Mayor de Callosa d'En Sarriá y Bolulla, y artificialmente mediante bombeos, fundamentalmente en los pozos de Beniardá. La última de las UHG que corresponden a la Marina Baja, la número 8.48, no sólo se alimenta de infiltraciones de agua de lluvia, sino que también recibe las aguas de otros cauces y caudales procedentes del embalse del Amadorio. Las salidas se producen de forma natural por los manantiales de Altea principalmente, y de manera artificial mediante bombeos. La UHG de Orcheta presenta riesgo de sobreexplotación y tiene problemas de intrusión marina $(\mathrm{CHJ}$, 1999), aunque según los últimos datos de la CHJ (2005b) no es de esperar la existencia de problemas serios en conjunto en el sistema de la Marina Baja. Esta UHG es compartida con el Sistema Vinalopó-Alacantí8.

A la hora de estimar los recursos subterráneos disponibles hay que tener en cuenta las modificaciones introducidas por la DMA en su artículo 2.27: «el recurso disponible de aguas subterráneas se define como el valor medio interanual de la tasa de recarga total de la masa de agua subterránea, menos el flujo interanual medio requerido para conseguir los objetivos de calidad ecológica para el agua superficial asociada, a fin de evitar cualquier disminución significativa en el estado ecológico de tales aguas y cualquier daño significativo a los ecosistemas terrestres asociados».

El PHCJ establece específicamente en su artículo 18 el mantenimiento de caudales mínimos que con carácter ecológico son exigibles aguas abajo de los principales embalses. Para el embalse de Guadalest, éste se fija en 100 1/s (CHJ, 1999; art. 35). Por tanto, para poder establecer lo que se ha definido como recurso disponible, además de calcular el volumen de los acuíferos, las descargas de agua subterránea a ríos, manantiales o al mar, para propósitos ambientales y seguir lo establecido por el PHCJ, se ha añadido una restricción ambiental adicional: las descargas laterales. Se ha considerado que el $80 \%$ de las transferencias laterales entre acuíferos, en ocasiones, constituyen una proporción significativa de los recursos disponibles (CHJ, 2005a). Por tanto, la diferencia entre los recursos renovables de cada masa de aguas subterránea -recarga por la filtración de lluvias, recarga por retornos de regadío, pérdidas en el cauce y $80 \%$ de las entradas/salidas laterales- y de los volúmenes ambientales requeridos, arrojan unas cifras para las UHG que afectan al sistema de explotación Marina Baja como las que siguen:

7 Esto explica que los recursos subterráneos disponibles para el sistema de explotación Marina Baja ronden los $40 \mathrm{hm}^{3}$ y el total obtenido de la suma de las tres UHG arroje unas cifras de $46 \mathrm{hm}^{3} /$ año, ya que no todos los recursos subterráneos obtenidos en la UHG son utilizados exclusivamente en el sistema Marina Baja.

8 PHCJ, Art. 12, Tomo I, Normativa, CHJ, (1999). 
Tabla 1. Recursos disponibles por UHG, para el sistema Marina Baja, en hm³/año

\begin{tabular}{|l|c|c|c|}
\hline \multicolumn{1}{|c|}{$\mathbf{N}^{\text {o de UHG }}$} & $\begin{array}{c}\text { Recurso } \\
\text { renovable }\end{array}$ & $\begin{array}{c}\text { Caudales } \\
\text { ambientales }\end{array}$ & $\begin{array}{c}\text { Recursos } \\
\text { disponibles }\end{array}$ \\
\hline 8.45: Sierra Aitana & $16^{\prime} 16$ & $0^{\prime} 63$ & $15^{\prime} 53$ \\
\hline 8.46: Serrella-Aixorta-Algar & $28^{\prime} 64$ & $5^{\prime} 64$ & $23^{\prime} 00$ \\
\hline 8.48: Orcheta & $9^{\prime} 09$ & $1^{\prime} 18$ & $7^{\prime} 91$ \\
\hline Total & $53^{\prime} 89$ & $7^{\prime} 45$ & $46^{\prime} 44$ \\
\hline
\end{tabular}

Fuente: CHJ, 2005b

Como ya hemos mencionado, los $46 \mathrm{hm}^{3}$ de aportaciones subterráneas procedentes de estas tres UHG no son utilizados íntegramente en la Marina Baja. La UHG de Serrella-Aixorta-Algar realiza aportes a los sistemas de explotación de la Marina Alta y Serpis, y la UHG de Orcheta, la número 8.48, es compartida entre los sistemas Marina Baja y Vinalopó-Alacantí.

En un esquema más detallado, los pozos que intervienen en el sistema general de utilización del agua en la Marina Baja son: el acuífero del Algar, cuyos caudales son bombeados hacia el embalse de Guadalest; el acuífero de Beniardá, aguas arriba del embalse de Guadalest; el de Orcheta, que resuelve parte del abastecimiento de Villajoyosa; el de Peña Alhama en Altea y los de Polop, situados en la Sierra Aitana, utilizados tanto para abastecimiento como para riego (Murillo y Castaño, 2003). De menor importancia son las perforaciones de Sella y Benimantell, que han sido las últimas en entrar en funcionamiento.

Otra forma de contabilizar los recursos disponibles en la Marina Baja es separarlos por sistemas, en lugar de por origen de los caudales. El sistema Algar-Guadalest está formada por el río Algar, el Guadalest y los acuíferos del Algar, Beniardá y Polop, caudales almacenados en el embalse de Guadalest. El sistema Amadorio recoge las escorrentías de los ríos Amadorio y su afluente el río Sella, y el acuífero de Aitana Sur. Además, este sistema recoge los sobrantes del sistema Algar-Guadalest, ya que las sobrantes de riego que se recogen aguas debajo de la estación de bombeo del Algar, así como las del río Guadalest son recogidas en la estación de bombeo del Mandem y conducidas por el canal bajo del Algar hasta el azud del río Torres. Desde este río, junto con sus escasas aportaciones, se impulsan hasta el embalse del Amadorio para su regulación (CAMB, 2005).

\subsection{Recursos disponibles no convencionales}

Las elevadas presiones sobre las masas de agua -creciente población, tanto residente como turista, la agricultura de regadío y, en menor medida, la de secano, la actividad industrial y la producción de energía hidroeléctrica- han provocado 
la necesidad de una utilización conjunta de recursos disponibles, tanto superficiales como subterráneos. Casos como los de La Plana de Castellón, la Ribera del Júcar y, por supuesto, la Marina Baja, son claros ejemplos (Sahuquillo, 1996). Pero esas presiones, además de provocar en ocasiones la sobreexplotación de acuíferos, han forzado la búsqueda de recursos alternativos para aumentar la cantidad de caudales disponibles; los denominados no convencionales. Éstos son la reutilización de las aguas residuales depuradas y la desalación de aguas marinas y salobres. La reforma del Plan Hidrológico Nacional a través del real decreto ley 2/2004 ha supuesto una modificación importante en la política hidráulica, introduciendo una regulación que impulsa la utilización de las aguas desaladas y reutilizadas en detrimento de los trasvases como solución a las situaciones de escasez en cuencas deficitarias (Prats y Melgarejo, 2006). El programa AGUA y la modificación del PHN por la ley 11/2005, de 22 de junio, plantean un cambio sustancial, ya que confían a los recursos no convencionales, como la desalación o la reutilización, la solución a los problemas de escasez de recursos hídricos existentes en algunos puntos del Sureste español.

Cabe distinguir, en primer lugar, dos conceptos que en ocasiones se utilizan como sinónimos cuando son en realidad complementarios. Uno de ellos es la depuración de las aguas residuales, proceso necesario para paliar la contaminación de las masas de agua, tanto superficial como subterránea, antes de seguir formando parte del ciclo hídrico. Otro proceso muy distinto es la reutilización para usos consuntivos de parte de esas aguas depuradas.

El destino de estas aguas, aparte del regadío, suele ser el uso urbano, que aunque no está permitido para consumo humano, sí para el riego de jardines, extinción de incendios, limpieza de calles, usos industriales como la refrigeración, usos ornamentales, etc. Desde el punto de vista legislativo, las referencias a la utilización de estos caudales quedan recogidas en el artículo 109 del TRLA: «[...] se establecerán las condiciones básicas para la reutilización de las aguas [así como que] el titular de la concesión o autorización deberá sufragar los costes necesarios para adecuar la reutilización de las aguas a las exigencias de calidad vigentes en cada momento»?.

En el apartado 2 del mismo artículo señala que «la reutilización de las aguas procedentes de un aprovechamiento requerirá concesión administrativa como norma general. Sin embargo, en el caso de que la reutilización fuera solicitada por el titular de una autorización de vertido de aguas ya depuradas, se requerirá solamente una autorización administrativa $[\ldots] »$.

9 Este apartado está redactado conforme a la disposición final primera de la ley 11/2005 de modificación del Plan Hidrológico Nacional, BOE, 149, de 23/06/2005. 
En España no existía una normativa que definiera los usos a los que se puede destinar el agua regenerada en función de su calidad. En diciembre de 2007 se aprobó el real decreto 1620/2007, de 7 de diciembre, por el que se establece el régimen jurídico de la reutilización de las aguas depuradas ${ }^{10}$. Hasta ese momento, se venía manejando desde 1999 un borrador de real decreto de criterios mínimos para la reutilización de efluentes depurados propuesto por el Ministerio de Medio Ambiente (en adelante, MIMAM). Parece que, finalmente, ese borrador se ha materializado en R.D.

Una de las exigencias para poder planificar las actuaciones de reutilización es la disponibilidad del efluente de las estaciones depuradoras. Las EDAR se han incrementado por la obligatoriedad de la directiva 91/271 CEE sobre el tratamiento de las aguas residuales urbanas, desarrollada en el Plan Nacional de Saneamiento y Depuración 2000-200511 que ha sido recientemente sustituido por el nuevo Plan Nacional de la Calidad de las Aguas 2007-2015 ${ }^{12}$. Este Plan es la pieza fundamental de planificación que tiene el MIMAM junto a las CCAA para la realización de las diferentes infraestructuras en materia de saneamiento y depuración, y que promueve garantizar la calidad del vertido. Con la promulgación de la ley 11/1995 y el real decreto 509/1996, se transponían al ordenamiento jurídico español todos los elementos normativos establecidos en la citada directiva, aunque a fecha de hoy, sea este Plan Nacional de la Calidad de las Aguas 2007-2015 el que establezca los criterios básicos a nivel estatal. Las CCAA han plasmado en sus disposiciones los criterios que deben ser aplicados a la hora de reutilizar estos caudales. En la Comunidad Valenciana, estos estándares vienen recogidos en el II Plan Director de Saneamiento y Depuración (Generalitat Valenciana, 2002).

La provincia de Alicante posee unas 145 plantas depuradoras, lo que supone una capacidad de depuración de aguas residuales de unos $170 \mathrm{hm}^{3} / a n ̃ o$. Por su parte, en la comarca de la Marina Baja existen actualmente 10 depuradoras

10 BOE número 294, de 8 de diciembre de 2007.

${ }^{11}$ Resolución de 28 de abril de 1995 de la Secretaría de Estado de Medio Ambiente y Vivienda, por la que se dispone la publicación del Acuerdo del Consejo de Ministros de 17 de febrero de 1995, por el que se aprueba el Plan Nacional de Saneamiento y Depuración de Aguas Residuales.

${ }^{12}$ El pasado viernes 8 de junio se ha dado el visto bueno al Plan Nacional de Calidad de las Aguas: Saneamiento y Depuración 2007-2015, que ha elaborado el Ministerio de Medio Ambiente, en colaboración con las Comunidades Autónomas. El nuevo Plan da respuesta tanto a los objetivos no alcanzados por el anterior, como a las nuevas necesidades planteadas por la Directiva Marco del Agua y por el Programa A.G.U.A. Forma parte de un conjunto de medidas que persiguen el definitivo cumplimiento de la directiva 91/271/CEE y que pretenden contribuir a alcanzar el objetivo del buen estado ecológico que la Directiva Marco del Agua exige para el año 2015. 
en funcionamiento. Para el análisis de datos hemos utilizado las tres EDAR principales en el sistema: la de Benidorm ${ }^{13}$, la de Altea y la EDAR de Villajoyosa, ya que entre las tres suponen el 98,4\% del total depurado en la comarca. La reutilización directa de las aguas residuales depuradas tiene una gran relevancia en el ámbito de la CHJ. Según datos de la Entitat de Sanejament d'Aigües, en 2004 se reutilizaron un total de $149 \mathrm{hm}^{3}$ de los $502 \mathrm{hm}^{3}$ depurados, lo que supone un 29,7\%. En Alicante, los caudales reutilizados representaron un 30 '6\% del agua total depurada en la provincia, lo que supone un 33'3\% del agua reutilizada en la Comunidad Valenciana (Prats y Melgarejo, 2006). Este porcentaje es superior en la comarca de la Marina Baja, donde la reutilización en el año 2005 alcanzó un porcentaje del 45\%, quince puntos por encima de la Comunidad Valenciana.

Debemos tener en cuenta que únicamente la reutilización directa de las aguas residuales cerca de la línea costera supone realmente un incremento de los recursos disponibles, ya que se utilizan unas aguas que de otra forma no se aprovecharían. Las aguas residuales depuradas en las áreas más interiores vierten a los cauces, formando parte, junto con las aportaciones naturales, de los recursos disponibles para otros usuarios aguas abajo (CHJ, 2005a). Es lo que se conoce como depuración indirecta.

Los volúmenes actuales reutilizados con datos del CAMB (2006) son del orden de los $6 \mathrm{hm}^{3} /$ año, quedando por tanto por debajo de las previsiones de la Generalitat Valenciana, que los situaba en $12 \mathrm{hm}^{3} /$ año según el II Plan Director (Generalitat Valenciana, 2002).

Tabla 2. Caudales depurados y reutilizados en la comarca de la Marina Baja, 2005 en m$^{3}$

\begin{tabular}{|l|c|c|c|}
\hline & $\begin{array}{c}\text { CAUDALES } \\
\text { DEPURADOS }\end{array}$ & $\begin{array}{c}\text { CAUDALES } \\
\text { REUTILIZADOS }\end{array}$ & $\begin{array}{c}\text { \% DE } \\
\text { REUTILIZACIÓN }\end{array}$ \\
\hline EDAR BENIDORM & 12.387 .290 & 3.387 .877 & 27,35 \\
\hline EDAR VILLAJOYOSA & 2.214 .551 & 1.623 .071 & 73,29 \\
\hline EDAR ALTEA & 3.060 .782 & 1.027 .359 & 33,57 \\
\hline TOTAL & 17.662 .623 & 6.038 .307 & 34,19 \\
\hline
\end{tabular}

Fuente: CAMB, 2006

${ }^{13}$ A partir del año 2005 entró en funcionamiento la nueva ampliación de la EDAR de Benidorm, aumentando el caudal de volúmenes tratados. El hecho de que en la Memoria del CAMB (2006) sólo aparezcan como caudales depurados en Benidorm unos 8.244.458, nos hace pensar que no se han contabilizado los depurados por esta nueva ampliación. Según datos de la propia EDAR de Benidorm, los caudales depurados en 2005 ascendieron a $12.387 .290 \mathrm{~m}^{3}$. 
Si los volúmenes totales tratados en las EDAR de la comarca de la Marina ascienden a $17 \mathrm{hm}^{3} /$ año, en principio podríamos hacernos una idea del elevado porcentaje entre aguas depuradas y reutilizadas para usos agrícolas. Aunque a priori este dato pudiera servir como indicador parcial de la efectividad en la utilización y el aprovechamiento de caudales en la zona de una manera integrada, tanto usuarios como el propio organismo no opinan igual. La reutilización de caudales depurados en la comarca de la Marina Baja depende de numerosos factores, entre los que destaca la pluviometría o los periodos de riego.

Los agricultores prefieren regar con caudales blancos siempre que éstos estén disponibles y sean lo suficientemente abundantes como para satisfacer la demanda urbana y los intercambios pactados en caso de necesidad con el CAMB, como veremos en capítulos posteriores. En presencia de recursos naturales abundantes, la utilización de caudales residuales depurados es menor, por lo que estas aguas actúan más como fuente sustitutiva que como complementaria, tal y como sugiere un modelo de GIRH. Por tanto, la mayor o menor utilización de caudales residuales depurados no es un buen indicador de la efectividad en la gestión para el caso de la Marina Baja.

Los siguientes gráficos corroboran el carácter sustitutivo de las aguas depuradas. Si observamos el agua consumida procedente de la depuración y los datos de las lluvias durante el año 2005 vemos que la relación es clara.

Los gráficos siguientes ponen de relieve la relación directa entre las lluvias registradas y los volúmenes reutilizados. Benidorm y Altea se ven más influidos por la evolución de las lluvias en las subcuencas del Guadalest y Algar, más húmedas, como indican los datos totales de lluvias recogidos, que ascienden a 361,80 y $342,201 / \mathrm{m}^{2}$ respectivamente; mientras que Villajoyosa pertenece a la subcuenca del Amadorio, con unas lluvias más regulares a lo largo de casi todo el año, aunque inferiores, unos $184,401 / \mathrm{m}^{2}$. Los niveles comienzan a descender a finales de año, coincidiendo con un aumento importante de las precipitaciones en la zona del Amadorio. En las subcuencas del Algar y Guadalest, las oscilaciones son mayores, y los meses más secos - mayo, junio, julio y agosto- coincidieron para el año 2005 con una intensificación de los caudales reutilizados, tanto los procedentes de la EDAR de Benidorm como de la de Altea. Hay que tener en cuenta que los periodos de riego de los productos de la comarca, localizados fundamentalmente en la época estival, afectan directamente a la necesidad de caudales disponibles.

Al igual que para Villajoyosa, los caudales reutilizados descienden a finales de año, coincidiendo con un aumento importante del nivel de precipitaciones, cambiando de tendencia en diciembre, mes en donde, de nuevo, vuelven a disminuir las lluvias en toda la comarca. 
Gráfico 1. Pluviometría por subcuencas 2005

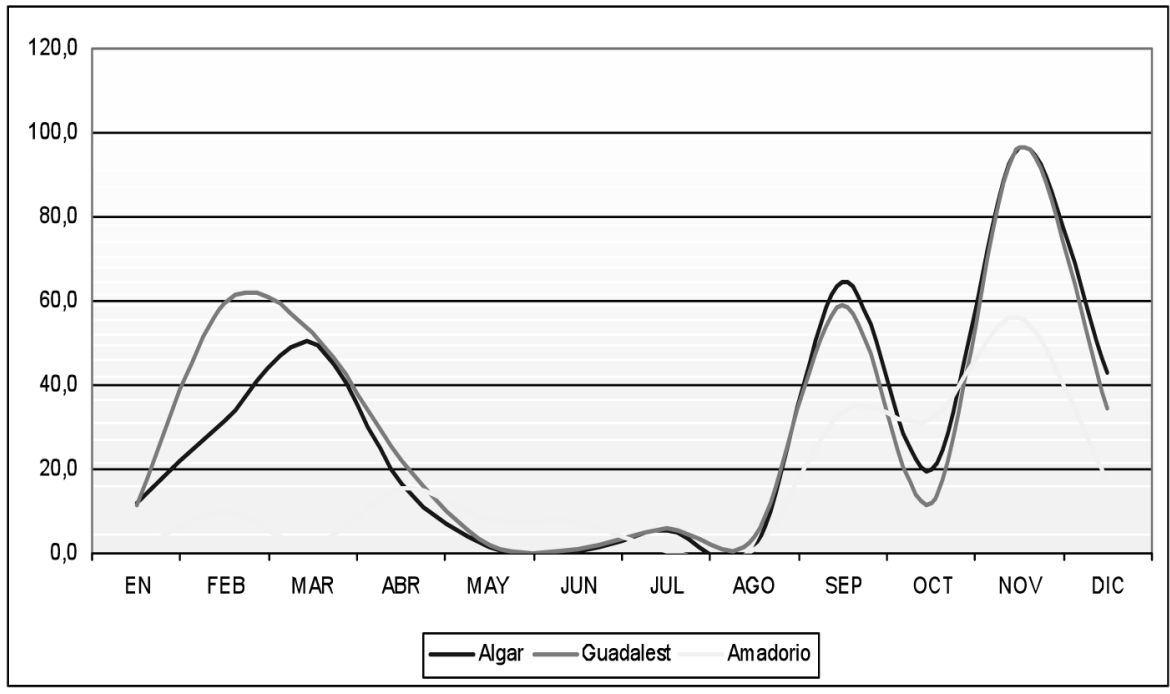

Fuente: CAMB, 2006. Elaboración propia

Gráfico 2. Caudales reutilizados en la Marina Baja, 2005

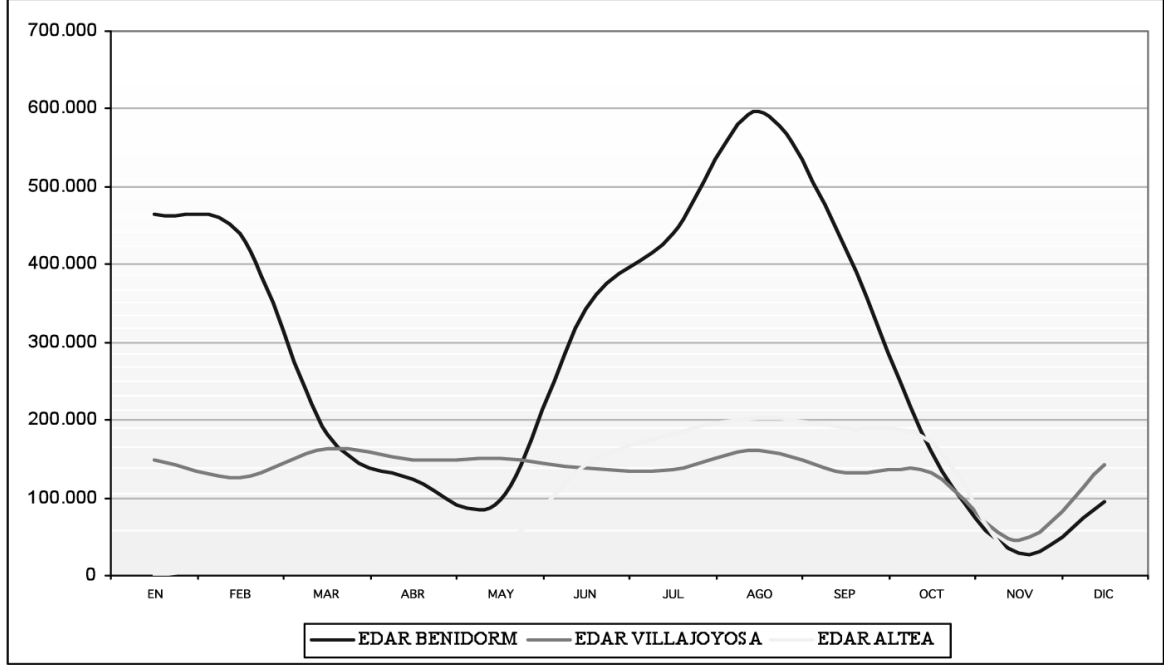

Fuente: CAMB, 2006. Elaboración propia

Los periodos de regadío son otro de los factores que determinan la utilización de recursos reutilizados en la comarca. Se ha determinado que de media, los consumos de agua para regadío se distribuyen como sigue:

Investigaciones geográficas, $n^{\circ} 48$, pp. 39 - 76 
Tabla 3. Porcentajes de distribución en los consumos de agua para regadío en la Marina Baja

\begin{tabular}{|c|c|c|c|c|}
\hline $\begin{array}{c}\text { \% Riego } \\
\text { trimestre }\end{array}$ & $\begin{array}{c}\text { \% CR } \\
\text { Villajoyosa 2006 }\end{array}$ & $\begin{array}{c}\text { \% CR } \\
\text { Villajoyosa 2005 }\end{array}$ & $\begin{array}{c}\text { \% CR } \\
\text { Canal Bajo }\end{array}$ & $\begin{array}{c}\text { \% } \\
\text { Media }\end{array}$ \\
\hline trim1 & 4,4 & 13,0 & 5,5 & 7,5 \\
\hline trim2 & 30,5 & 26,5 & 13,5 & 23,5 \\
\hline trim3 & 53,2 & 42,0 & 40,5 & 45,5 \\
\hline trim4 & 11,9 & 18,5 & 40,5 & 23,5 \\
\hline
\end{tabular}

Elaboración propia

Los datos nos muestran que es en el tercer trimestre del año -julio, agosto y septiembre-, cuando más agua se consume en la zona, siendo los meses en que se intensifica la demanda de caudales reutilizados, en función de la disponibilidad de caudales naturales.

La información anterior revela la importancia en el funcionamiento del sistema de la Marina Baja de los caudales reutilizados, aunque no estrictamente en el modo en que recomienda una GIRH. Su carácter, más sustitutivo que adicional, contribuye en el incremento de los recursos disponibles teóricos del sistema, equilibrando demandas y ofertas en la Marina Baja.

Otra de las fuentes de recursos denominados no convencionales son las aguas desaladas. Actualmente no existen recursos procedentes de la desalación en el sistema Marina Baja. Sin embargo, el anexo III del RD ley 2/2004 ${ }^{14}$ por el que fundamentalmente se derogaba el trasvase desde el Ebro, contempla entre las nuevas actuaciones de interés general la desalación de recursos en la Marina Baja. Estas nuevas medidas han sido posteriormente reflejadas en el programa A.G.U.A. del Ministerio de Medio Ambiente, donde entre las actuaciones e inversiones a realizar en la provincia de Alicante, por un valor de 618 millones de euros, se contempla la creación de una planta desaladora en Altea, aunque se ha modificado la localización de la planta para evitar la afección al Lugar de Interés Comunitario (LIC) de «Serra Gelada i Litoral de la Marina Baixa», así que, finalmente, la planta desaladora se localizará en Mutxamel15, comarca de L'Alacantí ${ }^{16}$.

${ }^{14}$ Real decreto ley 2/2004, de 18 de junio por el que se modifica la ley 10/2004, de 5 de julio del Plan Hidrológico Nacional. BOE 19.06.2004 (Anexo, III. 3b).

${ }^{15}$ La nueva planta se construirá en dos partes, las infraestructuras de captación de aguas marinas se localizará en el municipio costero de Campello, y el proceso de desalación en Mutxamel.

${ }^{16}$ Nota de prensa del MIMAM del 26 de marzo de 2007 y 25 de mayo de 2007. 


\subsection{Aportes externos}

Han sido varios los periodos críticos de escasez de recursos por los que ha atravesado la comarca de la Marina Baja antes de plantearse una gestión integrada de recursos. Uno de los más graves fue el que se produjo en el verano de 1978, donde una de las localidades más importantes de la zona, Benidorm ${ }^{17}$, tuvo que ser abastecida a través de barcos cuba del ejército del aire. Otra de las localidades de la comarca, Villajoyosa, tuvo que ser abastecida en octubre de ese mismo año a través de buques-cisterna ${ }^{18}$.

En principio, son escasos los aportes que recibe el sistema Marina Baja procedentes de otras cuencas. En situaciones de escasez, el CAMB ha solicitado autorización para recibir caudales a la Mancomunidad de Canales del Taibilla, utilizando para ello la conducción Rabasa-Fenollar-Amadorio, construida en 1995, que conecta las infraestructuras del Trasvase Tajo-Segura y el río Júcar con la comarca. Esta conducción ha sido utilizada en situaciones puntuales de emergencia para transportar caudales desde el Júcar, con carácter excepcional, en los años 1999, 2000, 2001 y 2002, transportando unos caudales totales de $6,3 \mathrm{hm}^{3}, 7,9 \mathrm{hm}^{3}, 10,9 \mathrm{hm}^{3}$ y $0,2 \mathrm{hm}^{3}$ respectivamente (CAMB, 2006). El sistema utiliza fundamentalmente caudales procedentes de acuíferos localizados en la comarca para su subsistencia, que son recargados por infiltración de agua de lluvia. La existencia de una infraestructura como la conducción Rabasa-FenollarAmadorio, funciona como garante del equilibrio del sistema en caso de pluviosidad escasa para la llegada de aportes externos.

Actualmente, la comarca de la Marina Baja no recibe aportes externos al sistema de explotación, pese a haber sido solicitados en numerosas ocasiones por la Junta General del CAMB y haber estado proyectada la llegada de caudales a la zona a través del controvertido trasvase Júcar-Vinalopó. Este trasvase, reclamado por los ilicitanos ya en 1420 y reiterado en numerosas ocasiones, se encuentra en estos momentos inmerso en un proceso de modificación. En 1997, el Plan Hidrológico del Júcar asignaba unos caudales de $80 \mathrm{hm}^{3}$ al sistema Vinalopó-Marina Baja reconociendo sus necesidades, si se generaban excedentes en el Júcar. Esta conducción se declaró de interés general, junto con otras actuaciones, y de prioridad, en virtud del RD-ley 9/1998, recogida en el Plan Hidrológico Nacional. El objetivo fundamental del proyecto era paliar la sobreexplotación a la que están sometidos los acuíferos y, en principio, acabar con los déficits en los abastecimientos de la zona. En el proyecto inicial se establecía que de los $80 \mathrm{hm}^{3}$ previstos, 11,5 irían a la comarca de la Marina Baja destinados exclusivamente a abastecimientos urbanos.

\footnotetext{
${ }^{17}$ Para más detalles consultar Diario Información, 27 de agosto de 1978.

${ }^{18}$ Diario Información, 6 octubre de 1978.
} 
Tabla 4. Distribución de la transferencia Júcar-Vinalopó (volumen inicialmente previsto de $80 \mathrm{hm}^{3} / \mathrm{año}$ )

\begin{tabular}{|l|c|c|c|c|}
\hline \multicolumn{1}{|c|}{ Usuario } & $\begin{array}{c}\text { Alto } \\
\text { Vinalopó }\end{array}$ & $\begin{array}{c}\text { Medio } \\
\text { Vinalopó }\end{array}$ & $\begin{array}{c}\text { Marina } \\
\text { Baja }\end{array}$ & $\begin{array}{c}\text { Dotación Total } \\
\text { (hm }\end{array}$ \\
\hline Riego 1 & 6,3 & 6,3 & & 12,6 \\
\hline Riego 2 & 6,3 & 26,1 & & 32,4 \\
\hline Total Riego & 12,6 & 32,4 & & 45,0 \\
\hline Abastecimiento 1 & 3,5 & 16,5 & & 20,0 \\
\hline Abastecimiento 2 & 0,5 & 3,0 & 11,5 & 15,0 \\
\hline $\begin{array}{l}\text { Total } \\
\text { Abastecimiento }\end{array}$ & 4,0 & 19,5 & 11,5 & 35,0 \\
\hline TOTAL & 16,6 & 51,9 & 11,5 & 80,0 \\
\hline
\end{tabular}

Fuente: Informe para la Comisión Europea sobre la conducción Júcar-Vinalopó (CHJ, 2004b)

Sin embargo, el 22 de febrero de 2006, Aguas del Júcar aprobó -basándose en el informe de la Comisión Técnica para la viabilidad del trasvase presentado en julio de 2005- la modificación del proyecto inicial del trasvase Júcar-Vinalopó. Alegando razones ambientales, se modificó entre otros aspectos la toma en el río Júcar, alterando las zonas receptoras finales. Mientras el proyecto inicial contemplaba a la comarca de la Marina Baja como receptora de 11,5 hm³/año, el proyecto actual sólo considera a las comarcas del Alto y Medio Vinalopó. Desde el Ministerio de Medio Ambiente se alega que las necesidades de la Marina Baja serán cubiertas gracias a las nuevas desaladoras proyectadas en el Programa AGUA para la zona, en principio, en el municipio de Altea -que ya hemos visto que se ha trasladado al municipio de Mutxamel-y la de Benidorm (Terra Mítica) que está en fase de construcción.

\section{USOS DEL AGUA. DEMANDA DE RECURSOS EN LA COMARCA DE LA MARINA BAJA}

Antes de establecer las demandas de agua en la zona es necesario comentar la composición socioeconómica de la comarca de la Marina Baja. Conocer la estructura de la población y las actividades económicas son cuestiones esenciales para poder entender las particularidades de usos y demandas de cada uno de los sectores implicados ${ }^{19}$.

${ }^{19}$ Un análisis semánticamente riguroso nos impediría hablar de demandas, ya que es cierto que en Europa no se puede hablar, al menos en términos exactos, de la existencia de mercados de agua, por lo que sería erróneo emplear expresiones como oferta y demanda de agua. Algo similar ocurre con los términos «déficits» y «superávits». Se puede hablar de consumos (Aguilera-Klink, 2000), pero no demandas en un sentido estricto. Sin embargo, la terminología habitual emplea el término para referirse a los consumos de cada uno de los usos identificados, por lo que vamos a seguir la tónica general. 
La actividad turística desde la década de los 1960, concentrada principalmente en la franja costera, ha provocado una creciente tendencia hacia la litoralización demográfica, con un incremento en la densidad de la zona costera frente a una progresiva despoblación en gran parte de las zonas interiores. La masa de población estacional que aparte del crecimiento de población fija se concentra en las costas, responde a dos movimientos: uno local, procedente de los núcleos más cercanos, y el otro exterior, desde otras regiones y países. En algunos municipios la incidencia de la población estacional es tan importante que llega a superar en determinados periodos a la población residente fija. Esto ocurre generalmente en los meses estivales en la provincia de Alicante, en las localidades de Denia, Teulada, Jávea, Calpe, Benidorm, Campello, Santa Pola, Guardamar o Torrevieja $\mathrm{a}^{20}$.

La comarca de la Marina Baja cuenta con una población de 171.877 habitantes, lo que supone el 9,4\% del total provincial. Benidorm concentra casi un $40 \%$ de la población de la comarca, y suma, junto con Villajoyosa y Altea, el $70 \%$ de toda la población residente. Por su parte, la población total abastecida por el Consorcio de Aguas de la Marina se cifra en unos 159.000 habitantes, con puntas estivales que oscilan entre los 234.000 y los 600.000 habitantes.

La evolución de la población en la comarca ha pasado por distintas fases. En los años 50 Benidorm inicia un desarrollo socioeconómico importantísimo gracias a un fenómeno sin precedentes, la actividad turística, creciendo a un ritmo incluso superior al de la propia capital. Una vez que el modelo turístico se consolida en Benidorm, comienza a extenderse a municipios costeros vecinos, como Altea, Alfaz o La Nucía. Es entre los años 1960 y 1975 cuando se produce el mayor crecimiento demográfico. A partir de ese año, como consecuencia de la crisis económica que sufre el país, este crecimiento se desacelera. En los años 1980, la generalización del control de la natalidad y la llegada de residentes extranjeros de edad avanzada comienza a provocar un progresivo envejecimiento de la estructura demográfica (Cámara de Comercio, 1996). Sin embargo, la Marina Baja se consolida como una de las comarcas más dinámicas de la provincia, con crecimientos muy superiores a la media provincial y al resto de comarcas.

\footnotetext{
20 Según el II Plan de Saneamiento y depuración de la Comunidad Valenciana, «[...] Estos datos sobre la estacionalidad tienen una importancia esencial en la planificación del saneamiento, ya que es necesario diseñar instalaciones de depuración para absorber la totalidad de los vertidos que se produzcan en verano y tratarlos adecuadamente, manteniendo su funcionalidad aunque el caudal a depurar sea superior al del resto del año. Lo mismo ocurre con las redes de colectores [...]» ( II PSD, p. 44).
} 
Gráfico 3. Evolución demográfica de la Marina Baja, 1990-2001

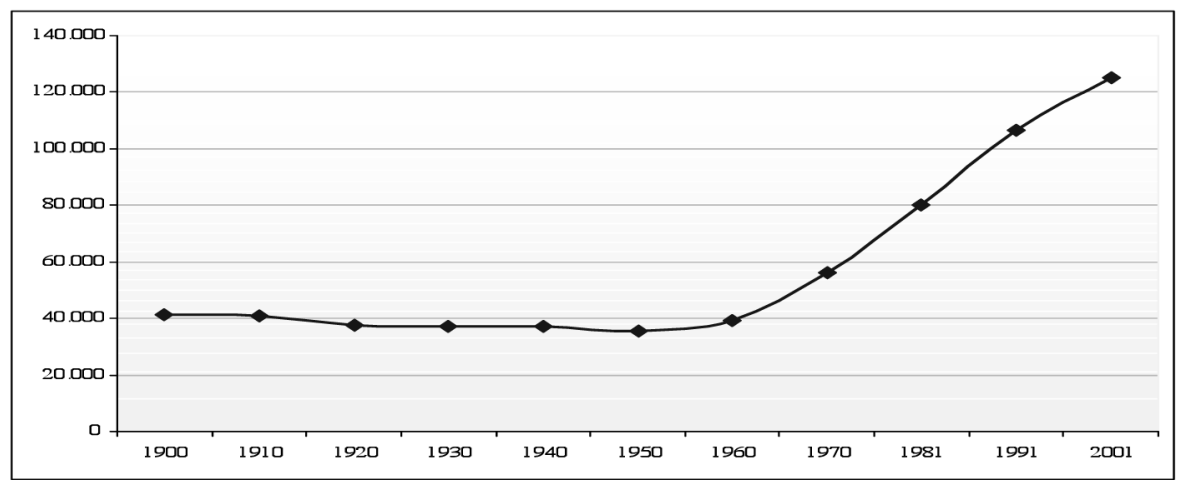

Fuente: INE. Elaboración propia

En general, la evolución de la población de la comarca de la Marina Baja durante el siglo XX queda reflejada en el gráfico anterior. Éste muestra claramente dos etapas diferenciadas. La primera de ellas va desde principios de siglo hasta finales de la década de los cincuenta, de tendencia ligeramente decreciente. Los motivos de este cuasi-estancamiento de la población de la comarca hay que buscarlos en los niveles de atraso del país y los movimientos migratorios hacia otras zonas más prósperas. La segunda etapa comienza a principios de los sesenta, en donde el boom turístico propició la llegada masiva de inmigrantes, de carácter laboral, procedentes de Andalucía, Murcia y Castilla en un primer momento, atraídos por los nuevos puestos de trabajo generados por el turismo y la construcción, y ya a finales de los setenta, inmigrantes procedentes de países europeos que eligen la costa española como lugar de residencia tras la jubilación (Sánchez et al., 2004). Los países de procedencia tradicionales comparten estos últimos años protagonismo con la zona del Magreb, Latinoamérica o Europa del Este, si bien la tipología de estos inmigrantes es distinta de los anteriores, ya que suelen ser trabajadores en activo.

\subsection{Sectores productivos y marco económico}

La descripción de los sectores productivos es otro de los aspectos clave que nos ayudan a entender mejor las características particulares de la demanda de agua en nuestra zona de estudio. En general, podemos establecer una clara diferenciación en el ámbito territorial de la CHJ, trasladable al sistema Marina Baja. Por un lado, un sector agrario que ocupa una superficie total de 1.988 .890 ha, lo que supone un 46,2\% del uso del suelo según datos del 
CORINE $^{21}$, 2000 (MIMAM, 2005b). Por otro, una fuerte interacción entre el sector industrial y el de servicios, propiciada por la expansión de las actividades turísticas (CHJ, 1999).

\section{Sector agrario}

El sector agrario, con una demanda de recursos hídricos de casi un 80\%, es el sector que menos aporta al VAB, siendo de apenas un 3\% de total. Este sector ha sufrido importantes transformaciones desde los años 1960, debido fundamentalmente a la mecanización del sector, en particular del secano, que ha favorecido un traspaso de mano de obra agrícola hacia otros sectores: industria y servicios, capaces de absorber esta fuerza de trabajo, potenciando aún más la mecanización del sector agrícola (CHJ, 1999). Esta mecanización, junto con la introducción de nuevas tecnologías, ha propiciado un cambio de cultivos, desarrollándose nuevas áreas de regadío en zonas tradicionales de secano. La enorme demanda de agua desde este sector hace imprescindible la utilización de aguas residuales adecuadamente depuradas y con niveles de calidad suficientes como nueva fuente de recursos, sobre todo en aquellas zonas afectadas por graves déficits hídricos (II Plan Director de Saneamiento).

La estructura agraria también ha sufrido un proceso de transformación. Las explotaciones familiares van dejando paso a las cooperativas, y a ello había que sumar la aparición de sociedades agrarias de transformación, de transporte para la exportación de productos agrarios y de embalado.

La importancia de este sector en cuanto a la garantía y regularidad de inputs básicos como el agua, pasa por su enorme sensibilidad ante la evolución de la coyuntura económica, al ser un sector muy ligado a la producción de bienes de consumo y con un fuerte componente exterior ${ }^{22}$.

La agricultura se extiende por casi la mitad del territorio de la demarcación; las zonas de secano ocupan el 36\% del territorio, y las de regadío el 10\%, aproximadamente unas 350.000 ha (CHJ, 2005a). Dentro de los cultivos de regadío de la Comunidad Valenciana, los cítricos destacan en importancia, seguidos por los frutales y las hortalizas. Estos tres cultivos ocupan el 94\% de la superficie total destinada al regadío (II Plan Director de Saneamiento). Si nos fijamos en la provincia de Alicante, los porcentajes varían notablemente. Los cultivos de

${ }^{21}$ El proyecto CORINE (Coordination of Information on the Environment) Land Cover, desarrolla la creación de una base de datos sobre la cobertura y uso del territorio en la Unión Europea.

${ }^{22}$ Más del 2\% de las exportaciones españolas tienen su origen en la provincia de Alicante, porcentaje de participación que se eleva al $4 \%$ cuando hablamos de exportaciones agrícolas (Cámara de Comercio de Alicante, 2005a y CHJ, 1999). 
regadío ocupan una extensión de 123.432 hectáreas y los de secano 136.822 (MAPA, 2004), lo que supone que sólo el 47,4\% de los cultivos en la provincia son de regadío. La aportación de la agricultura al VAB es del 4,22\% sobre el total (Cámara de Comercio de Alicante, 2005a), ligeramente superior al porcentaje que representa esta actividad en la demarcación hidrográfica.

En la comarca de la Marina Baja, la estructura de los cultivos queda como sigue:

Tabla 5. Superficies de cultivo en secano y regadío. Año 2005 (ha)

\begin{tabular}{|l|r|r|r|r|r|r|}
\hline & \multicolumn{2}{|c|}{ Total Herbáceos } & \multicolumn{2}{c|}{ Total Leñosos } & \multicolumn{2}{c|}{ Total tierras cultivo } \\
\cline { 2 - 7 } & secano & \multicolumn{1}{|c|}{ regadío } & secano & \multicolumn{1}{c|}{ regadío } & secano & \multicolumn{1}{c|}{ regadío } \\
\hline Zona CAMB* & 8 & 34 & 268 & 2.210 & 276 & 2.244 \\
\hline Marina Baja & 8 & 63 & 5.640 & 4.204 & 5.648 & 4.267 \\
\hline
\end{tabular}

* Los municipios que forman parte del Consorcio de Aguas de la Marina Baja son Altea, Alfaz del Pí, Benidorm, Finestrat, La Nucía, Polop y Villajoyosa.

Fuente: Informes Agrarios de la Consellería de Agricultura, Pesca y Alimentación. 2002-2005. Elaboración propia

El 43\% de la superficie cultivada en la comarca de la Marina Baja es de regadío, centrado casi exclusivamente en el cultivo de cítricos, frutales -fundamentalmente nísperos- y olivar.

\section{Construcción y servicios. La actividad turística}

En la comarca de la Marina Baja, el desarrollo del turismo está íntimamente ligado al sector de la construcción y la promoción inmobiliaria. A excepción de Benidorm, donde la oferta hotelera es muy amplia, el modelo turístico de la comarca se basa en la existencia de una amplia oferta extrahotelera. Tanto la tipología de las viviendas en la comarca, con un 30,2\% de porcentaje de segunda residencia sobre el total, como la clasificación del alojamiento nos dan una idea aproximada del modelo turístico y, por tanto, de la demanda de agua asociada.

La provincia de Alicante es la primera potencia turística de la Demarcación Hidrográfica. La aportación del sector servicios al VAB, centrada fundamentalmente en la actividad turística, es de un 63,89\%, representando el 60,23\% del empleo provincial (Cámara de Comercio, 2005a). La mayor parte de esta aportación al VAB se concentra en unos pocos municipios costeros alicantinos. Si observamos algunos indicadores económicos en la zona, uno de los más llamativos en su composición es el indice turístico ${ }^{23}$. La elevada concentración de la

${ }^{23}$ El índice turístico se calcula en función de la cuota tributaria (IAE), teniendo en cuenta el número de habitaciones, la ocupación anual y la categoría de los establecimientos turísticos (Vera et al., 2004). 
actividad turística en la provincia viene demostrada por el hecho de que los diez municipios con un índice turístico más elevado suponen el 90\% del índice total de la provincia de Alicante. Es más, de esos diez, cinco pertenecen a la comarca de la Marina Baja, con un porcentaje sobre el índice turístico provincial de casi el 70\%. Benidorm solamente, tiene un índice turístico que supone el 61,5\% del total de la provincia de Alicante. Con estos datos es sencillo comprender la importancia que la actividad turística posee para una comarca como la que nos ocupa en este trabajo.

La relación entre la actividad turística y el agua es especialmente conflictiva en el caso del turismo popularmente conocido como de «sol y playa», que es el modelo que impera en la Comunidad Valenciana en general. Las mismas características climáticas que hacen atractivos este tipo de destinos son las que propician la mayor parte de los problemas relacionados con la existencia de recursos hídricos insuficientes para atender la demanda generada. La provincia de Alicante se ha especializado tradicionalmente en el turismo de masas, con un poder adquisitivo medio o bajo, lo que ha influido en la calidad del producto ofertado (Vera et al., 2004). La estacionalidad en la demanda es otra de las características del sector turístico alicantino, con los problemas que sobre la utilización de recursos y la infrautilización de infraestructuras a menudo tienen asociados. La solución propuesta en los años 1980 y 1990 para acabar con los problemas de estacionalidad, el llamado turismo de invierno -bajos precios con mucha ocupación-, no se sostiene frente a destinos más baratos y con bajos costes laborales, por lo que, según informaciones publicadas recientemente, «[...] los empresarios basarán su estrategia futura en adaptar su oferta para potenciar el mercado nacional $»^{24}$.

De entre todos los municipios alicantinos, Benidorm es el distrito turístico por excelencia. Con el $80 \%$ de las plazas totales ofertadas en la comarca de la Marina Baja, es el núcleo turístico central. Pero no sólo a escala comarcal, sino que representa un $41 \%$ de las plazas ofertadas en la provincia de Alicante y un $21 \%$ de las existentes en toda la Comunidad Valenciana. A la hora de determinar la demanda de agua por sectores, hemos de tener en cuenta la existencia de una oferta extrahotelera ${ }^{25}$, por lo general no reglada, pero cuya incidencia en la de-

${ }^{24}$ Diario Información, martes 25 de abril de 2006.

${ }^{25}$ Siguiendo a Fuertes et al., (1999, p. 33), para el cálculo de la demanda de agua de origen extrahotelero se han contemplado las residencias secundarias de los municipios costeros. No se consideran las segundas residencias de municipios del interior, porque se suponen ocupadas por habitantes de la propia Comunidad que en su día se trasladaron hacia centros urbanos, y en vacaciones, suelen regresar a sus lugares de origen. Por tanto, la ocupación de segundas residencias de lugares del interior no supone un incremento de la demanda de recursos hídricos, sino más bien un desplazamiento espacial de la misma. 
manda total de recursos en la zona es relevante dado el modelo turístico desarrollado. Pero la enorme oferta de plazas hoteleras contrasta con otros municipios donde la estructura del alojamiento pasa por una creciente importancia de las plazas extrahoteleras.

\section{DEMANDA DE RECURSOS}

Son numerosas las fuentes que aportan datos sobre los recursos disponibles y demandas hídricas a todos los niveles, y casi nunca coinciden en las cifras. Nuestro propósito es recoger los últimos datos publicados por los organismos oficiales para, posteriormente, compararlos con los obtenidos empíricamente en la zona objeto de estudio, sobre todo, en cuanto a demanda urbana se refiere. Los condicionantes de cada una de las demandas merecen un tratamiento por separado, considerando de este modo las particularidades que en cada caso forman la demanda total por sectores.

\subsection{Demanda agrícola}

El análisis del regadío juega un papel fundamental a la hora de establecer la demanda de agua para uso agrícola. En España la aportación de las producciones de las tierras en regadío a la Producción Final Agrícola suponen más del $50 \%$ de ésta, mientras que la superficie que ocupan sólo representa el 15,01\% de la superficie agrícola útil (MAPA, 2006). La preferencia por el regadío viene avalada por los datos económicos, dado que una hectárea de regadío produce seis veces más que una de secano y genera una renta cuatro veces superior -relación que se incrementa en el caso de cultivos de invernadero y bajo plástico-. Además, la larga tradición del uso del agua en la agricultura española se manifiesta en la distribución actual de los regadíos: algo menos de un tercio de la superficie regada tiene carácter histórico por ser anterior al siglo XX, el resto de la superficie se distribuye entre las transformaciones acometidas por la iniciativa pública y privada ${ }^{26}$. La apuesta desde la Administración General del Estado por mejorar la eficiencia del mayor consumidor de agua se ha plasmado en el Plan Nacional de Regadíos (PNR), cuyas actuaciones se llevan a cabo bien a través de sus propios medios o bien por medio de las Sociedades Estatales de Infraestructuras Agrarias (SEIASAS) ${ }^{27}$. Una de las acciones prioritarias del

${ }^{26}$ Según el MAPA (2006) un 28\% de la superficie regada tiene la consideración de carácter histórico, un $37 \%$ son de iniciativa pública y un 34\% privada.

${ }^{27}$ Fueron creadas con la ley 50/1998, de 30 de diciembre, de Medidas Fiscales, Administrativas y del Orden Social, en su artículo 99 denominado «Creación de Sociedades mercantiles estatales para la ejecución de obras e infraestructuras de modernización y consolidación de regadíos», con las siguientes funciones: 
PNR es la modernización de los regadíos, a través de la implantación de sistemas de riego localizado -que han crecido un 434\% entre 1989 y 2005- y por aspersión, mucho más eficientes que los tradicionales riegos por gravedad. Aunque se ha recorrido mucho camino en la modernización del regadío, todavía queda mucho por hacer en algunas comunidades autónomas. Mientras comunidades como Murcia poseen un $76 \%$ del riego localizado, otras como Asturias, Navarra, Galicia y Madrid realizan todavía el $80 \%$ de los riegos por gravedad (MAPA, 2006).

Pese a que pueda parecer lo contrario por las situaciones de déficits argumentadas desde algunas zonas peninsulares, las hectáreas de regadío en España han aumentado un 8,7\% desde los años noventa. Sin embargo, la reducción en las hectáreas de secano -14,5\% desde 1990- explica el resultado decreciente de las tierras de cultivo en España, que han pasado de algo más de 20.000 hectáreas en los noventa a las 18.000 en 2003.

Como viene siendo habitual en todo lo relacionado con los temas hídricos, no existe consenso en cuanto a las dotaciones a aplicar por tipo de cultivo y hectárea para calcular las demandas agrícolas. Las dotaciones brutas en la mayor parte del territorio de la CHJ oscilan entre los 4.000 y los $8.000 \mathrm{~m}^{3} / \mathrm{ha} /$ año (CHJ, 2004a). Un ejemplo de esta variabilidad lo vemos en las dotaciones para los cítricos, el cultivo más importante en cuanto a extensión y valor total de la producción. Mientras que el texto único del PHCJ establece una dotación media en la comarca de la Marina Baja de unos $4.120 \mathrm{~m}^{3} / \mathrm{ha}$, Melgarejo et al. (2004) apuntan a valores que superan los $8.000 \mathrm{~m}^{3}$ por hectárea -en concreto 8.364 $\mathrm{m}^{3} / \mathrm{ha}$-. Lo que es cierto es que «cuanto más azúcar más dulce», pero hay datos más acordes con la situación actual que establecen dotaciones bastante menores. Datos del estudio «Los déficits hídricos y su impacto económico en los cultivos de regadío» (MAPA, 2005) ofrecen unas cifras de $3.845 \mathrm{~m}^{3}$ por hectárea para el área de riego Algar-Guadalest.

Ante la falta de concordancia entre cifras publicadas, hemos optado por trabajar con aquéllas que, debido a los parámetros que utilizan, son más específicas

a) La financiación, en concurrencia con la iniciativa privada, de las obras de modernización y consolidación de los regadíos que se contemplen en el ámbito del Plan Nacional de Regadíos.

b) La promoción, contratación y explotación, en su caso, de las obras mencionadas en el párrafo anterior, en la forma en que se determine en sus normas de creación y estatutos.

c) La coordinación de las actividades relacionadas con las referidas obras.

En noviembre de 1999, el Consejo de Ministros autorizaba la creación de los 4 organismos: Seiasa del Norte, Seiasa del Nordeste, Seiasa de la Meseta Sur -en cuyo ámbito de actuación nos encontramos-, y la Seiasa del Sur y el Este. 
de la comarca objeto de estudio. El Servicio de Tecnología para el Riego, dependiente de la Consellería de Agricultura, Pesca y Alimentación ${ }^{28}$, muestra unas dotaciones medias para las estaciones de Altea y Villajoyosa de $5.047,75 \mathrm{~m}^{3} /$ ha/año ${ }^{29}$. Expertos agrícolas han confirmado que las necesidades medias de los cítricos están en torno a los $5.000 \mathrm{~m}^{3} / \mathrm{h} a /$ año.

Para determinar la demanda de agua para regadío en la comarca de la Marina Baja, es necesario señalar que, de todos los municipios que componen la comarca, el que destina más hectáreas de suelo a uso agrícola de regadío es Callosa d'En Sarriá, tanto en términos absolutos como en términos relativos, ya que las hectáreas de regadío suponen casi un 32\% de todo el término municipal, el más elevado de los que componen la comarca.

Pese a que en los últimos años la tendencia de las hectáreas destinadas al regadío ha sido ligeramente decreciente, y la agricultura está en claro retroceso, la superficie destinada al regadío en el municipio de Callosa ha experimentado un fuerte crecimiento cercano a un 300\% desde $1978^{30}$ desarrollando una agricultura especializada en cítricos y nísperos -426 y 654 hectáreas respectivamente de las 1.110 hectáreas de superficie destinada al regadío-.

Los cítricos son la principal producción agrícola de la Comunidad Valenciana con 178.676 hectáreas de superficie y una producción de más de tres millones de toneladas, lo que supone el 20\% de la superficie y la producción en la provincia de Alicante. A escala comarcal, de las 2.064 hectáreas ocupadas por cítricos, Callosa y Villajoyosa con 426 y 405 hectáreas respectivamente, seguidas de cerca por Altea con 378, son las principales productoras.

El otro gran cultivo de la comarca de la Marina Baja es el níspero, localizándose en la provincia de Alicante el 78\% de las hectáreas destinadas a este cultivo en la Comunidad Valenciana y el 90\% de la producción de esta fruta. Callosa es

${ }^{28}$ Estos datos se calculan utilizando un programa denominado PARloc (disponible en http:// www.agricultura.gva.es/riego/index.html) que toma en consideración características propias tanto de los cultivos - marco de plantación, diámetro de la copa, coeficiente de cultivo medio, factor de aprovechamiento de la lluvia, caudal medio por planta, etc.- como de la estación de referencia -régimen de lluvias, evapotranspiración técnica de referencia, temperatura, pérdidas estimadas en función del tipo de suelo, condiciones de la instalación, calidad del agua, etc.-. En nuestro caso, hemos utilizado las dotaciones que aparecen para registradas en las estaciones de Altea y Villajoyosa, localidades ambas dentro de la comarca.

${ }^{29}$ Hemos obtenido una cifra media dado que la dotación también depende de tipo de riego, localizado o por gravedad.

${ }^{30}$ Estos incrementos han sido calculados utilizando los mapas de cambio de uso de suelo desde los años 50 en la comarca de la Marina Baja. Para una descripción más detallada ver Sánchez et al., 2004 y Peña, et al. 2005. 
la principal productora de nísperos ${ }^{31}$, con más del $50 \%$ de la superficie comarcal y el $60 \%$ de sus tierras de regadío, siendo el gran producto de su economía local, y a gran distancia de Altea y Polop, donde encontramos 169 y 127 hectáreas de nísperos respectivamente. Es decir, de las 4.267 hectáreas destinadas a cultivos de regadío en la comarca de la Marina Baja, 2.367 hectáreas corresponden a cítricos, fundamentalmente naranjas, y 1.780 son ocupadas por frutales, básicamente nísperos.

A la hora de analizar la gestión del agua en la comarca de la Marina Baja es interesante definir correctamente a los usuarios de los recursos. Si bien para la demanda urbana es primordial conocer la población y otras variables tales como la importancia de actividades económicas o la composición de determinados sectores, para el caso de la demanda agrícola es más correcto hablar de comunidades de regantes y las hectáreas que gestionan, que de municipios. Por tanto, hemos identificado como individuos relevantes en el funcionamiento de la comarca a seis comunidades de regantes -algunas de ellas son Comunidades Generales, por lo que aglutinan a más de una comunidad de regantes, aunque emplearemos como término genérico la comunidad de regantes para todos- y no sólo porque abarcan prácticamente la totalidad del ámbito de cultivo de la comarca, sino por su participación activa junto con el CAMB en el modelo de funcionamiento de la Marina Baja.

De las analizadas ${ }^{32}$, las más importantes son, la Comunidad General de Regantes y Usuarios de Callosa D'En Sarriá, la Comunidad de Regantes del Canal Bajo del Algar, y la Comunidad de Regantes de Villajoyosa, siendo las más modestas en cuanto a hectáreas regadas la Comunidad de Regantes de Altea, la Comunidad de Regantes de Polop y la Comunidad de Regantes de La Nucía.

La determinación de la demanda de agua para el sector agrícola pasa por, una vez conocida la estructura organizativa del sector, aplicar las dotaciones teóricas elegidas a las hectáreas cultivadas. Los cultivos principales, como hemos indicado, son los cítricos y los frutales, principalmente el níspero. Según las cifras de la Consellería, el consumo de agua destinado al cultivo de cítricos rondaría los 11,95 $\mathrm{hm}^{3}$ anuales. Para el caso de los nísperos, como era de esperar, disponemos de varias cifras de necesidades según las fuentes consultadas, ocupando un rango desde los $5.000 \mathrm{~m}^{3} / \mathrm{ha} /$ año facilitado por la Cooperativa Agrícola Ruchey de Callosa d'En Sarriá,

${ }^{31}$ El 14 de Enero de 1992 los nísperos de Callosa d'En Sarriá fueron distinguidos con la Denominación de Origen: «Nísperos Callosa d’En Sarriá»

${ }^{32}$ Para una información más detallada sobre las comunidades de regantes mencionadas véase Torregrosa, T. (2007) «El modelo socioeconómico de gestión de los recursos hídricos en la comarca de la Marina Baja (Alicante); un enfoque de GIRH». Tesis Doctoral, Departamento Análisis Económico Aplicado, Universidad de Alicante. 
hasta los $8.957 \mathrm{~m}^{3} /$ ha/año que según Sánchez et al, (2004) les facilitaron los agricultores de la zona. Los datos de la Consellería a través del Servicio de Tecnología del riego ${ }^{33}$ son bastante inferiores a los anteriores, indicando unas dotaciones medias de $3.257 \mathrm{~m}^{3} / \mathrm{h}$ a/año, lo que supone un consumo anual de unos $6 \mathrm{hm}^{3}$.

Ante la disparidad en los datos sobre dotaciones, hemos determinado considerar tres fuentes oficiales distintas. En primer lugar, un estudio publicado por el Ministerio de Agricultura, Pesca y Alimentación en 2005 (MAPA, 2005, anejo 16), donde aparecen las dotaciones para cada una de las áreas de riego diferenciadas por confederaciones hidrográficas para cada tipo de cultivo. En segundo lugar, las dotaciones netas por comarca que establece el PHCJ (CHJ, 1999, anexo 2 de la Normativa), y por último, hemos consultado el programa PARloc de asesoramiento de riego localizado por tipo de cultivo para cada una de las estaciones agroclimáticas diferenciadas dentro de la Comunidad Valenciana, de la Consellería de Agricultura, Pesca y Alimentación a través del Servicio de Tecnología del Riego. La tabla 6 resume las dotaciones obtenidas para cada tipo de cultivo.

Si aplicamos a la superficie cultivada las dotaciones medias de las tres observaciones anteriores, el consumo teórico para la comarca queda muy por debajo de las cifras publicadas tanto por cada una de las Comunidades de Regantes como por el propio Consorcio. Esto parece lógico, ya que a esas dotaciones teóricas habría que sumarle los caudales que se pierden por la evapotranspiración, las fugas y el agua no controlada.

Si consideramos un escenario más pesimista, donde utilicemos las dotaciones netas máximas de todas las disponibles para la zona en lugar de la media, las cifras de consumo se modifican al alza de forma sustancial, como era de esperar, llegando a los $21 \mathrm{hm}^{3}$. Pero aun así, queda por debajo de esos $25,7 \mathrm{hm}^{3}$ de consumo agrícola según las cifras publicadas por el CAMB en 2005.

Los datos anteriores, elaborados a partir de las hectáreas contabilizadas en el Informe Agrario Valenciano (2005), corroboran, al menos con la precisión que los datos nos permiten, los totales aportados por el CAMB (2006) que vienen recogidos en la tabla siguiente, en cuanto a consumo de agua para uso agrícola en la comarca de la Marina Baja. Según el CAMB, tenemos unos 25,7 hm³ y según nuestros datos, aplicando dotaciones máximas, el consumo agrícola alcanza los $21,1 \mathrm{hm}^{3}$. Cifras ambas muy alejadas de esos $33 \mathrm{hm}^{3}$ inicialmente publicados por la CHJ en el año 2000 y que han sido corregidos a la baja en 2007 hasta los $24 \mathrm{hm}^{3}$ anuales de consumo agrícola en la comarca. La importancia de la dispa-

${ }^{33}$ Datos obtenidos a partir del programa PARloc del Servicio de Tecnología del Riego, www. agricultura.gva.es/riego, 2007. 


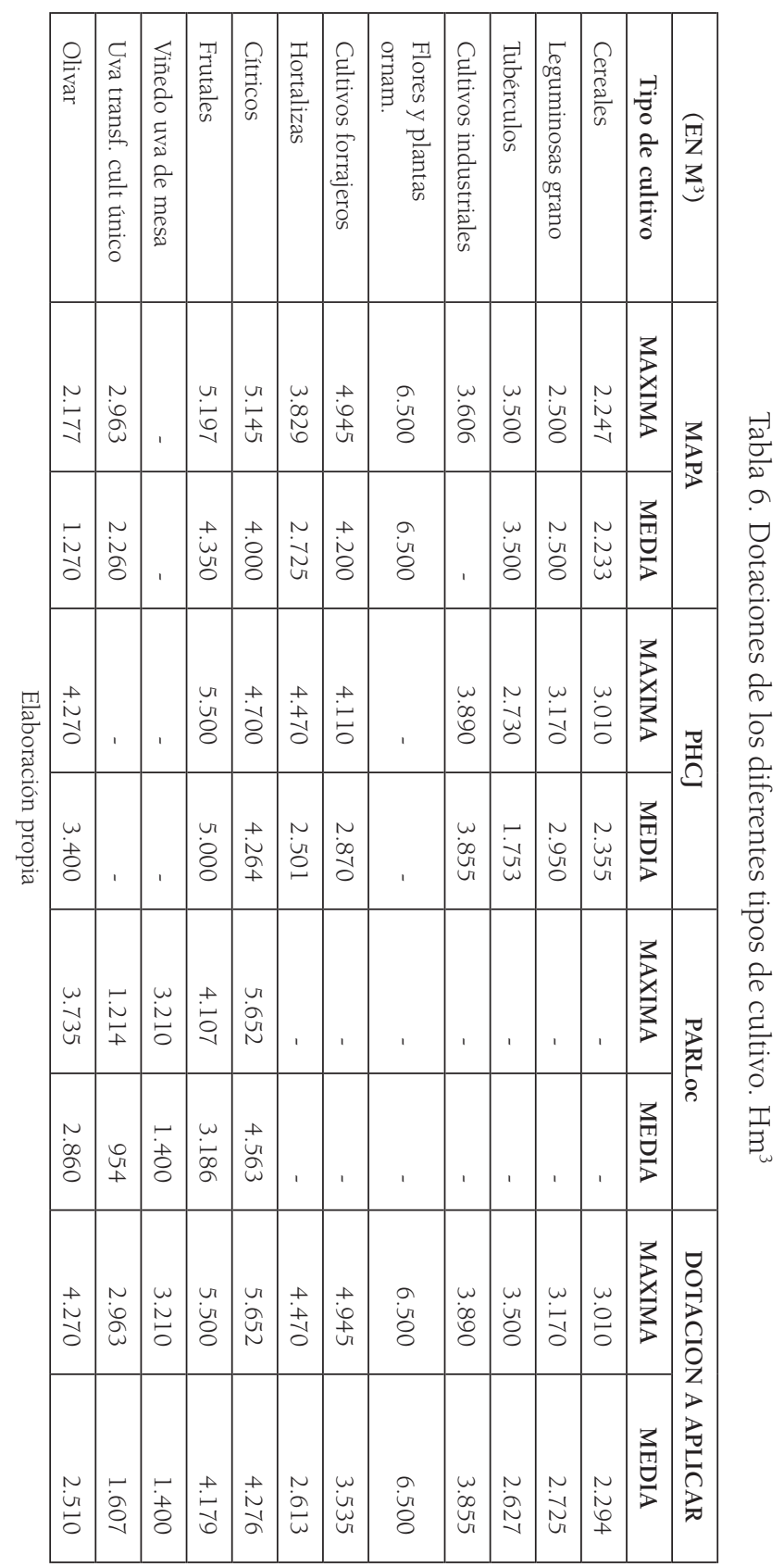


ridad de datos no es meramente un desajuste de cifras. Esos $33 \mathrm{hm}^{3}$ anuales de consumo de agua para uso agrícola fueron utilizados para justificar la necesidad del trasvase Júcar-Vinalopó hasta la comarca de la Marina Baja en función del déficit de recursos calculado con estos datos.

Tabla 7. Consumo teórico de las diferentes CR en base a sus cultivos.

\begin{tabular}{|c|c|c|c|c|c|}
\hline & \multirow{2}{*}{$\begin{array}{c}\text { TOTAL } \\
\text { HERBÁCEOS } \\
\text { (Ha regadío) }\end{array}$} & \multirow{2}{*}{$\begin{array}{l}\text { TOTAL } \\
\text { LEÑOSOS } \\
\quad(\text { Ha } \\
\text { regadío })\end{array}$} & \multirow{2}{*}{$\begin{array}{l}\text { TOTAL } \\
\text { (Ha en } \\
\text { regadío) }\end{array}$} & \multicolumn{2}{|c|}{ TOTAL CONSUMO $\left(\mathrm{m}^{3}\right)$} \\
\hline & & & & $\begin{array}{c}\text { dotaciones } \\
\text { medias }\end{array}$ & $\begin{array}{c}\text { dotaciones } \\
\text { máximas }\end{array}$ \\
\hline CR CANAL BAJO & 22,0 & $1.063,5$ & $1.085,5$ & $4.570 .441,5$ & $6.051 .054,0$ \\
\hline CR VILLAJOYOSA & 102,0 & 711,0 & 813,0 & $2.912 .191,0$ & $4.031 .601,0$ \\
\hline CR CALLOSA & 11,0 & $1.099,0$ & $1.110,0$ & $4.657 .807,0$ & $6.152 .792,0$ \\
\hline CR ALTEA & 6,0 & 290,0 & 296,0 & $1.236 .170,5$ & $1.641 .693,0$ \\
\hline CR POLOP & 0,0 & 311,0 & 311,0 & $1.287 .264,0$ & $1.710 .456,0$ \\
\hline CR LA NUCIA & 1,0 & 273,0 & 274,0 & $1.153 .856,0$ & $1.529 .156,0$ \\
\hline TOTAL & 142,0 & $3.747,5$ & $3.889,5$ & $15.817 .730,0$ & $21.116 .752,0$ \\
\hline
\end{tabular}

Fuente: Informe Agrario Valenciano 2005. Elaboración propia

Tabla 8. Consumo de agua para riego y origen en la comarca de la Marina Baja, 2005

\begin{tabular}{|c|c|c|c|c|c|c|}
\hline \multirow{2}{*}{$\begin{array}{c}\text { Comunidad de } \\
\text { Regantes }\end{array}$} & \multicolumn{2}{|c|}{$\begin{array}{c}\text { AGUAS } \\
\text { REUTILIZADAS }\end{array}$} & \multicolumn{2}{|c|}{$\begin{array}{l}\text { AGUAS } \\
\text { BLANCAS }\end{array}$} & \multicolumn{2}{|c|}{ TOTAL } \\
\hline & $\mathrm{m}^{3}$ & $\%$ & $\mathrm{~m}^{3}$ & $\begin{array}{c}\% \\
\text { sobre } \\
\text { total }\end{array}$ & $\mathrm{m}^{3}$ & $\%$ \\
\hline CR Canal Bajo Algar & 2.410 .843 & 46,0 & 2.829 .933 & 54,0 & 5.240 .776 & 100,0 \\
\hline CR Villajoyosa & 2.404 .312 & 67,3 & 1.167 .213 & 32,7 & 3.571 .525 & 100,0 \\
\hline CR Altea & 1.027 .359 & 38,1 & 1.665 .911 & 61,9 & 2.693 .270 & 100,0 \\
\hline CR La Nucía & 195.793 & 38,6 & 311.920 & 61,4 & 507.713 & 100,0 \\
\hline $\begin{array}{l}\text { TOTAL CONSUMO } \\
\text { MIXTO }\end{array}$ & 6.038 .307 & 50,3 & 5.974 .977 & 49,7 & 12.013 .284 & 100,0 \\
\hline \multicolumn{7}{|l|}{ Consumo aguas blancas } \\
\hline CG Callosa d'En Sarriá & 0 & & 11.515 .390 & 100,0 & 11.515 .390 & 100,0 \\
\hline CR Polop & 0 & & 2.181 .900 & 100,0 & 2.181 .900 & 100,0 \\
\hline $\begin{array}{l}\text { TOTAL CONSUMO } \\
\text { BLANCAS }\end{array}$ & 0 & & 13.697 .290 & & 13.697 .290 & \\
\hline $\begin{array}{l}\text { TOTAL CONSUMO } \\
2005\end{array}$ & 6.038 .307 & & 19.672 .267 & & 25.710 .574 & \\
\hline
\end{tabular}

Fuente: CAMB, 2006 y entrevistas con las comunidades de regantes. Elaboración propia 
Más de la mitad del consumo total corresponde a las Comunidades de Regantes de Callosa y el Canal Bajo del Algar, seguidas de cerca por Villajoyosa. En cuanto a los orígenes de los caudales, salvo las Comunidades de Regantes de Callosa y Polop ${ }^{34}$ que consumen exclusivamente aguas blancas, el resto reparten la procedencia de sus caudales entre aguas blancas y depuradas, contribuyendo de este modo, como veremos en apartados posteriores, al mantenimiento del equilibrio del sistema.

\section{Demanda industrial}

Ya hemos indicado que la demanda de agua para usos industriales, si bien no deja de tener su importancia a escala de cuenca y provincial, para el caso de la comarca de la Marina Baja es poco significativa. La pequeña y mediana industria suele establecerse en polígonos industriales, con lo que su demanda queda englobada dentro de la demanda urbana (Fernández-Montes, Torregrosa y González, 2004). Las dificultades que plantea el cálculo de las demandas industriales queda perfectamente reflejado en el Libro Blanco del Agua (MIMAM, 2000, p.252) «Existe [...] un escaso conocimiento sobre la demanda real de cada una de las industrias, debido a su gran dispersión (tanto territorial como sectorial), a la propia complejidad del uso industrial, y a la falta de controles estadísticos sistemáticos sobre el consumo de agua, más allá de la facturación en el caso en que se adquiera de la red municipal». Esto hace que se establezcan las dotaciones de manera indirecta, bien en función de la superficie ocupada, si se trata de polígonos industriales, o en función del número de empleados, método este último aplicado por la $\mathrm{CHJ}$ para establecer las demandas industriales en la demarcación hidrográfica. Según la CHJ, la demanda de agua para usos agrícolas en la cuenca, asciende a unos $147 \mathrm{hm} /$ año, calculados a partir del número de personas ocupadas -356.555- y con unas dotaciones de 11,22 $\mathrm{m}^{3} / \mathrm{empleado/día}$ (CHJ, 2005a).

La demanda de agua para usos industriales en la comarca de la Marina Baja se sitúa alrededor de $0,2 \mathrm{hm}^{3} / \mathrm{anno}^{35}$. Sin embargo, comparativamente a las otras

\footnotetext{
${ }^{34}$ Aunque Callosa, como se mencionará más adelante, dejó de pertenecer legalmente al CAMB como tal en 1992, sigue siendo un punto clave en la gestión de la zona, y dentro del área de influencia del CAMB, ya que en su término municipal se localiza una de las fuentes principales de recursos de la comarca: el acuífero del Algar. Tanto Callosa como Polop han llegado a acuerdos especiales con el Consorcio para consumir exclusivamente las aguas blancas a que tienen derecho según sus concesiones, a cambio de permitir al CAMB la utilización tanto del acuífero del Algar como el de Polop.

35 Para una descripción detallada sobre los datos industriales obtenidos por comarcas y total provincial véase Fernández-Montes, Torregrosa y González, (2004).
} 
demandas y dadas las dificultades y particularidades en su cálculo, creemos que es una cifra no excesivamente precisa ni suficientemente relevante para su inclusión por separado en el cómputo final, por lo que vamos a considerarlo de manera implícita en la demanda urbana.

Demanda urbana

La demanda urbana es quizá la más compleja de analizar. En zonas costeras como la que nos ocupa, el componente estacional es muy elevado; la población llega a cuadruplicarse en municipios turísticos en periodos estivales sobre todo. La demanda urbana comprende los recursos necesarios para abastecer a la población fija, a la industria incluida en los centros urbanos y los correspondientes al sector turístico, directamente relacionados con la población estacional $^{36}$.

Los requerimientos básicos de agua para uso urbano son: beber, higiene, servicios sanitarios y preparación de alimentos los cuales varían de un país a otro. Gleick (1996) ${ }^{37}$ propuso un mínimo de 50 litros por habitante y día, aunque esto depende de los niveles de bienestar alcanzados, clima, disponibilidad o accesibilidad a los recursos, tecnología, precios, legislación, etc. Países como Nigeria apenas pueden asegurar unos $30 \mathrm{l} / \mathrm{p} / \mathrm{d}$.

Pero la variación no depende sólo del país, sino de las regiones dentro de cada país y, sobre todo, como vamos a ver, de las fuentes consultadas.

La dotación por habitante y día es una magnitud sujeta a controversia. La variación es enorme en función de las fuentes. Éstas pueden ir desde los 125 l/ hab./día establecidos como mínimo en el artículo 17 del PHCJ, los 168 1/hab./ día según la encuesta de AEAS (2002), o los 171 de media española publicados por el INE ${ }^{38}$, hasta los 541 1/hab./día contabilizados para el municipio de Benidorm o los 678 de Teulada según Vera Rebollo et al. (2004). El 17 de agosto de 2006, el INE emitía una nota de prensa con el titular «El consumo medio de agua aumenta un 2,4\% durante el año 2004 y se sitúa en 171 litros por habitante y día».

La demanda urbana de agua para la provincia de Alicante se establece en unos 187,8 hm³/año (Fernández-Montes et al., 2004), y según los mismos au-

${ }^{36}$ En este apartado nos vamos a limitar a señalar las demandas que aparecen publicadas, para luego hacer un análisis más exhaustivo y comparar los datos obtenidos de forma empírica con los publicados por organismos oficiales.

${ }^{37}$ Citado en Butler y Fayyaz (2006, p. 4).

${ }^{38}$ Para la Comunidad Valenciana esta cifra asciende, según el INE, a 178 l/h/d, en 2004, lo que supone un incremento del 9,2\% con respecto a las cifras de 2003. www.ine.es agosto de 2006. Datos referentes a 2004. 
tores, el consumo para la comarca de la Marina Baja rondó los 25 hm³ en 2001, cifra bastante inferior a la aportada por el Plan de Saneamiento de la Comunidad Valenciana y la CHJ (2005a) que sitúan en unos $40 \mathrm{hm}^{3}$ los caudales urbanos consumidos en la comarca. Esta cifra ha sido corregida al alza por la $\mathrm{CHJ}$ en 2007, situando el consumo urbano de agua en la comarca de la Marina Baja en unos $47 \mathrm{hm}^{3}$.

Según el CAMB, el consumo de los municipios consorciados fue de 24,8 $\mathrm{hm}^{3}$ para 2004 (CAMB, 2005) y de 25,55 hm³ para 2005 (CAMB, 2006). Como vemos, las diferencias son abismales: casi el doble de consumo en función de la fuente. De forma empírica, y realizando unos cálculos de aproximación para estimar cuál de los dos consumos se acerca más a la realidad de la comarca -25 $\mathrm{hm}^{3}$ o 47-podemos utilizar las cifras de población y el consumo, para obtener las dotaciones medias por habitante y día de forma que:

Tabla 9. Población comarcal entre los años 2001 y 2004

\begin{tabular}{|l|r|r|r|r|}
\hline \multicolumn{1}{|c|}{ Municipio } & \multicolumn{1}{|c|}{2001} & \multicolumn{1}{c|}{2002} & \multicolumn{1}{c|}{2003} & \multicolumn{1}{c|}{2004} \\
\hline $\begin{array}{l}\text { TOTAL Población } \\
\text { CAMB (2) }\end{array}$ & 134.066 & 142.923 & 150.769 & 150.858 \\
\hline $\begin{array}{l}\text { TOTAL Población } \\
\text { MB (2) }\end{array}$ & 138.171 & 147.039 & 154.939 & 155.487 \\
\hline $\begin{array}{l}\text { Consumo CAMB } \\
\mathrm{m}^{3}(1)\end{array}$ & $22.828 .181,0$ & $22.680 .686,0$ & $23.754 .088,0$ & $23.760 .081,0$ \\
\hline $\begin{array}{l}\text { Consumo total MB } \\
\mathrm{m}^{3}(1)\end{array}$ & $23.527 .162,7$ & $23.333 .860,8$ & $24.411 .083,4$ & $24.489 .146,8$ \\
\hline $1 /$ hab/día $[(1) /(2)]$ & 170,3 & 158,7 & 157,6 & 157,5 \\
\hline
\end{tabular}

Fuente: INE. Elaboración propia

Esta tabla indica que el consumo para abastecimiento de agua en la comarca de la Marina Baja se acerca más a las cifras aportadas por Fernández-Montes et al., (2004), unos $25 \mathrm{hm}^{3} /$ año, que los $47 \mathrm{hm}^{3}$ establecidos en los documentos de la $\mathrm{CHJ}$.

Benidorm es el municipio de mayor importancia en la comarca, siendo también el mayor consumidor, con una demanda cercana al 52\% del consumo total. Durante la época estival, el consumo pasa de un valor medio anual de $32.000 \mathrm{~m}^{3}$ a un consumo punta de $52.000 \mathrm{~m}^{3}$ (CAMB, 2005).

\section{BALANCE DE SITUACIÓN}

Con los datos que acabamos de exponer, el balance de situación en la demarcación del Júcar y, en concreto, del sistema de explotación Marina Baja, queda como sigue: 


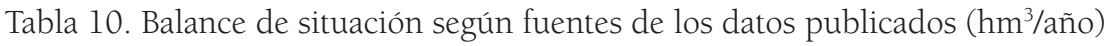

\begin{tabular}{|c|c|c|c|}
\hline & $\begin{array}{c}\text { Demarcación del } \\
\text { Júcar } \\
\left(\mathrm{CHJ}^{*}, 2007\right)\end{array}$ & $\begin{array}{c}\text { Sistema Marina } \\
\text { Baja } \\
\left(\mathrm{CHJ}^{*}, 2007\right)\end{array}$ & $\begin{array}{c}\text { Sistema Marina } \\
\text { Baja } \\
\text { (CAMB, 2006) }\end{array}$ \\
\hline \multicolumn{4}{|c|}{ Recursos Disponibles } \\
\hline Superficiales & 820 & 7 & 19,25 \\
\hline Subterráneos & 2.269 & 26 & 39,67 \\
\hline Depurados & $450(1)$ & 12 & 13,52 \\
\hline Desalados & 38,5 & - & - \\
\hline Total recursos disponibles & $3.577,5$ & 45 & 72,44 \\
\hline \multicolumn{4}{|c|}{ Demandas } \\
\hline Urbana & 676 & 47 & 25,5 \\
\hline Industrial & 181(2) & - & $0,5(2)$ \\
\hline Agrícola & 2.821 & 26 & 25,71 \\
\hline Ambiental & $430(3)$ & 7 & 7 \\
\hline Total demandas & 4.108 & 80 & 58,21 \\
\hline Balance & $-530,50$ & -35 & 14,23 \\
\hline
\end{tabular}

* Datos aportados por la Comisaría de Aguas de la CHJ en mayo 2007.

(1) En el año 2003, en las 300 estaciones depuradoras de aguas residuales se depuraban del orden de $450 \mathrm{hm}^{3} / a n ̃ o$, de los cuales, en la Comunidad Valenciana, $126 \mathrm{hm}$ 3/año se reutilizaban para uso preferentemente agrícola.

(2) Las industrias demandan un volumen total de $147 \mathrm{hm}^{3} /$ año, a los que hay que sumar los $24 \mathrm{hm}^{3} /$ año de demanda consuntiva asociada a la central nuclear de Cofrentes (CHJ, 2006b). Para el caso de la Marina Baja, esos 0,5 hm³ se computan dentro de la demanda urbana por no disponer de los datos desagregados.

(3) Datos correspondientes a volúmenes de reserva por razones medioambientales (CHJ, 2006b).

Elaboración propia

Esta tabla nos ofrece una visión muy sencilla de cómo los déficits o superávits de los sistemas hidrográficos pueden variar en función del origen de los datos considerados. El déficit contabilizado para el total de la demarcación del Júcar sería matizable. Por ejemplo, los volúmenes desalados contabilizados en la Comunidad Valenciana son del orden de $38,5 \mathrm{hm}^{3} /$ año, aunque la propia CHJ (2006a) informa que se prevé un aumento de la capacidad de producción a corto plazo hasta los $58,4 \mathrm{hm}^{3} / a n ̃ o$. Si además sumamos los caudales externos a la cuenca, que suponen unos $30 \mathrm{hm}$ 3/año desde la cuenca del Segura utilizados en el Bajo Vinalopó y l'Alacantí, el déficit inicial de 530,5 se reduce a los 480,6 hmªnuales ${ }^{39}$. Si, ade-

${ }^{39}$ Habría que sumar a los recursos disponibles 19,9 de incremento de recursos desalados -ya está en funcionamiento actualmente la desaladora de San Pedro del Pinatar y en construcción la de Torrevieja-, más los 30 que llegan de la cuenca del Segura, lo que reduce el déficit a los 480,6 $\mathrm{hm}^{3}$ en una primera fase. 
más, atendemos a lo establecido en el real decreto 287/2006, de 10 de marzo, por el que se regulan las obras urgentes de mejora y consolidación de regadíos ${ }^{40}$, en su anexo figuran una serie de actuaciones conjuntas entre el Ministerio de Medio Ambiente y el de Agricultura, Pesca y Alimentación, que de llevarse a cabo todas ellas, supondrán un ahorro del orden de 147 hm³/año en la Comunidad Valenciana. Con todo, el déficit señalado se situaría en unos $333,6 \mathrm{hm}^{3}$ anuales, de los 530,5 inicialmente planteados.

En la comarca de la Marina Baja los resultados son todavía más delicados si cabe, ya que la procedencia de los datos no sólo reduciría el déficit inicial planeado de los $35 \mathrm{hm}^{3}$ anuales, sino que pasaríamos a una situación de superávit importante en todo el sistema. Es muy difícil justificar la diferencia de cifras entre una y otra fuente, por ejemplo, para el caso de la demanda urbana, que va desde los $47 \mathrm{hm}^{3}$ que señalaba la CHJ en 2007 -o los 40 de la Generalitat en 2002-a los 25,5 reales según los datos -creemos bastante más acertados- aportados por tres fuentes distintas: Fernández- Montes et al (2004) desde Aquagest Levante, CAMB (2006) y cálculos propios. Incluso podríamos ser menos optimistas en cuanto a los datos de demanda de abastecimiento urbano, si atendemos a una reducción del orden de $1 \mathrm{hm}^{3}$ en lo que al consumo del municipio de Callosa d'En Sarriá se refiere. Este municipio, no perteneciente al CAMB desde 1992, nos ha facilitado unas cifras de consumo urbano que rondan los $0,6 \mathrm{hm}^{3}$ anuales, frente al 1,6 que estima el CAMB, quedando entonces las cifras de consumo urbano del orden de los $24,5 \mathrm{hm}^{3}$ y el superávit en más de $14 \mathrm{hm}^{3}$ anuales.

$\mathrm{Si}$, además, corregimos los datos de disponibilidad de recursos procedentes de la reutilización, éstos pasarían de ser 13,53 hm³ anuales, a 17,6 $\mathrm{hm}^{3}$ si incluimos los caudales proporcionados por la ampliación de la EDAR de Benidorm a finales de 2004 y que no están contabilizados en la memoria del CAMB del año 2005 , de donde se han extraído estos $13,53 \mathrm{hm}^{3}$. Por lo tanto, el superávit aumentaría hasta los más de $18 \mathrm{hm}^{3}$ anuales.

\section{CONCLUSIONES. ANÁLISIS DE LA INTEGRACIÓN DEL MEDIO FÍSICO, MEDIANTE A UNA GIRH}

Con todo lo descrito en los apartados anteriores, lo que nos queda es realizar el diagnóstico de la situación en función de los datos disponibles y de un modelo de GIRH, comprobando si las premisas que se han considerado como necesarias para una integración del medio físico, concurren en la comarca de la Marina Baja.

${ }^{40} \mathrm{BOE} \mathrm{n}^{\circ} 60$, de 11/03/2006. 
Considerábamos que la utilización conjunta de recursos supone el uso planeado y coordinado de diversas fuentes. La proporción en que se combinen las cantidades de agua de una y otra procedencia dependerá de la época del ciclo hidrológico natural, de las reservas existentes en el sistema tanto superficial como del almacenamiento de los acuíferos, la calidad disponible y, sobre todo, del objetivo fijado en la explotación del sistema (MIMAM, 2000).

Como ya se ha mencionado, el sistema de explotación Marina Baja está formado por los dos embalses, el Guadalest y el Amadorio, y las unidades hidrogeológicas de Serrella-Aixorta-Algar, Sierra Aitana y Orcheta. Los datos disponibles muestran que la utilización integrada en el sistema es prácticamente completa, aunque habría que matizar el adjetivo conjunta. En ocasiones es muy difícil distinguir la procedencia exacta de los caudales, ya que los embalses almacenan el agua procedente de la escorrentía superficial, junto con los caudales bombeados desde los acuíferos subterráneos. El conjunto Algar-Guadalest recoge los caudales superficiales de esos ríos y las aguas bombeadas desde los acuíferos del Algar, Beniardá y Polop, almacenados en el embalse de Guadalest. El sistema Amadorio, por su parte, recoge las escorrentías de los ríos Amadorio y su afluente el Sella, y los procedentes del acuífero de Aitana Sur. Estos caudales se inyectan en las conducciones generales como las de Guadalest, que abastece a prácticamente todos los municipios de la comarca, la del Amadorio y el Canal Bajo del Algar para riego. Igualmente, la conducción de reutilización construida en 1994 transporta los caudales procedentes de las EDAR de los municipios costeros para ser utilizados también en el riego. Queda por tanto establecida la integración de los caudales disponibles en la comarca.

La integración en los caudales destinados al riego es la más relevante en la zona, ya que casi la totalidad de los regadíos de la comarca utilizan aguas mixtas para el regadío. A estos caudales se le suman progresivamente las aguas reutilizadas procedentes de las EDAR del sistema Marina Baja, aunque más que una utilización conjunta, en este caso hablaríamos de sustitución, ya que los agricultores ceden las aguas blancas que tienen concedidas a cambio de recibir estos caudales reutilizables ${ }^{41}$ y ciertas compensaciones económicas ${ }^{42}$, una de

${ }^{41}$ Los riegos de los municipios de Callosa d'En Sarriá y Polop no participan de este tipo de intercambio, por lo que son, de todos los municipios integrados en el CAMB, los únicos que no utilizan caudales reutilizados para riego, evitando con esto la contaminación de los acuíferos más importantes del sistema, los Sondeos de Polop, y el Algar, en Callosa.

${ }^{42}$ Para conocer en detalle el esquema de funcionamiento de los intercambios en la comarca de la Marina Baja, ver Torregrosa, T. (2007) «El modelo socioeconómico de gestión de los recursos hídricos en la comarca de la Marina Baja (Alicante); un enfoque de GIRH». Tesis Doctoral, Departamento Análisis Económico Aplicado, Universidad de Alicante. 
las muchas particularidades que han contribuido a mantener el equilibrio en la comarca.

Para el caso de la demanda urbana de agua ${ }^{43}$ el análisis de la demanda para usos urbanos nos muestra que los datos publicados por la CHJ (2005a), al igual que ocurre con la demanda de agua para uso agrícola, son excesivos, en nuestra opinión, y los datos empíricos difieren.

La demanda de agua urbana calculada queda bastante alejada de las cifras de la CHJ, unos $24 \mathrm{hm}^{3}$ para la comarca de la Marina Baja, frente a los $47 \mathrm{hm}^{3}$ recientemente publicados por la CHJ (2007, Anexos, p. 76).

Pero lo más interesante en el análisis de la integración de los recursos disponibles es una visión de conjunto. El importantísimo incremento de población desde los años sesenta -de unos 40.000 habitantes en 1960 a los más de 177.000 en 2006- coincidiendo con el desarrollo espectacular de la actividad turística en la comarca, ha marcado la pauta de crecimiento económico, y de una demanda que llega incluso a tener que satisfacer a cerca de 600.000 habitantes en verano. La intensa actividad turística y el crecimiento poblacional con claro reflejo en la demanda urbana, junto con la importante actividad agrícola en la comarca, son dos de los sectores clave. El consumo entre ambos se reparte, según datos publicados, casi a partes iguales, en contra de la tónica nacional, donde el porcentaje de consumo es de dos tercios del total para uso agrícola frente a un tercio para uso urbano. El análisis de las demandas de ambos sectores arroja conclusiones reseñables en la comarca, donde observamos que se ha podido satisfacer la demanda de una población que se ha más que cuadriplicado, al mismo tiempo que se han mantenido casi intactas las hectáreas de regadío, aumentando de forma importante en zonas concretas como Callosa, sin recibir aportes externos, salvo en muy contadas ocasiones, y no contar con aguas desaladas ${ }^{44}$ y con prácticamente los mismos recursos naturales, utilizando para ello fórmulas de negociación entre el CAMB, responsable de la mayor parte del abastecimiento en alta, y las comunidades de regantes más importantes en el sistema, a través del intercambio de caudales blancos a los que por ley corresponde su concesión a los regantes, por caudales depurados aptos para el riego. Las particularidades de cada uno de estos acuerdos y su análisis permiten comprobar cómo se ha establecido un equilibrio entre recursos-demandas, prácticamente cerrado a los caudales externos.

${ }^{43}$ Partiendo de la consideración de que la demanda de agua para uso industrial va a ser parte de la urbana, dado el tejido industrial en la comarca de la Marina Baja.

${ }^{44}$ Los únicos caudales desalados provienen de la ampliación de la EDAR de Benidorm, y lo que hace es mejorar la calidad y reducir la conductividad de los caudales depurados. 


\section{BIBLIOGRAFÍA}

Butler, D. y Fayyaz Ali Memon (2006): Water Demand Management. IWA Publishing, Londres.

Cámara de Comercio de Alicante (1996): Informe socioeconómico territorial de la provincia de Alicante. La Marina Baja. Gabinete de Estudios de la Cámara de Comercio de Alicante, Alicante.

Cámara de Comercio de Alicante (2005a): Déficit Hídrico en la Provincia de Alicante y necesidad del trasvase Júcar-Vinalopó. Gabinete de Estudios de la Cámara de Comercio de Alicante, Alicante.

Cámara de Comercio de Alicante (2005b): Informe Económico 2004. Gabinete de Estudios de la Cámara de Comercio de Alicante, Alicante.

CAMB (2005): «Aprovechamiento Integral de los Recursos de la zona de la Marina Baja» Francisco Santiago Andrés, Ingeniero Director del CAMB. Jornadas sobre las Desaladoras, Escuela Politécnica Superior de Orihuela. Abril 2005, Orihuela.

CAMB (2006): Memoria del Consorcio para Abastecimiento y Saneamiento de la Marina Baja. CAMB, Callosa d'En Sarriá.

CAMB (2007): Informe Anual 2006. Consorcio de Aguas de la Marina Baja. Callosa d'En Sarriá.

CHJ (1999): Plan Hidrológico de la cuenca del Júcar. Ministerio de Medio Ambiente. Confederación Hidrográfica del Júcar. Valencia.

CHJ (2004a): Seguimiento del Plan Hidrológico de Cuenca del Júcar. Documento de Sintesis. Confederación Hidrográfica del Júcar. Oficina de Planificación Hidrológica. Valencia.

CHJ (2004b): Informe para la Comisión Europea sobre la conducción Júcar-Vinalopó. Comunidad Valenciana (España). Diciembre 2004.

CHJ (2005a): Informe para la Comisión Europea sobre los artículos 5 y 6 de la Directiva Marco del Agua. Abril. Demarcación Hidrográfica del Júcar. Confederación Hidrográfica del Júcar. Abril de 2005. Disponible online: http://www.chj.es/ web/pdf/DMA_Art5\&6_Jucar.pdf.

CHJ (2005b): Informe sobre el Balance del año hidrológico 2004-2005. Confederación Hidrográfica del Júcar, Oficina de Planificación Hidrológica, Área de Explotación SAIH. Valencia.

CHJ (2006a): Pliego de cláusulas administrativas particulares y prescripciones técnicas particulares que regirán en la oferta publica de la Confederación Hidrográfica del Júcar para la adquisición de derechos de agua en el tramo medio de la cuenca del río Júcar por razones ambientales. Disponible online: http://www.chj.es/OPAdDerAg/PliegoJucarOPAD_web.pdf. 
CHJ (2006b): Evaluación Ambiental estratégica de los Planes Especiales de Actuación en situaciones de alerta y eventual sequía cuenca hidrográfica del Júcar, Documento inicial. Diciembre de 2006.

Fernández-Montes, C.; Torregrosa, T. y GonzÁlez, A. (2004): «Demanda hídrica consolidada y evolución esperada. Abastecimientos e industria». En J. Melgarejo (ed) Repercusiones Socioeconómicas del Plan Hidrológico Nacional en la Provincia de Alicante. Fundación COEPA, Alicante.

Generalitat Valenciana (2002): II Plan Director de Saneamiento y Depuración de la Comunidad Valenciana. Disponible online en: http://www.cop.gva.es/espa/ hidra/plandirector/pdfs/IIPlanSaneamiento.pdf

Global Water Partnership (2000): Integrated Water Resource Management. Technical Advisory Committee. Background Paper, 4. Estocolmo.

Jonch-Clausen, T. y Fugl, J. (2001): «Firming up the Conceptual Basis of Integrated Water Resources Management», en Water Resources Development, Vol 17. No 4. pp. 501-510.

MAPA (2005): Los déficits hídricos y su impacto económico en los cultivos de regadío. Dirección General de Desarrollo Rural, Ministerio de Agricultura, Pesca y Alimentación, Madrid.

MAPA (2006): Hechos y cifras de la agricultura, la pesca y la alimentación en España. Secretaría General Técnica, Ministerio de Agricultura, Pesca y Alimentación, Madrid.

Melgarejo, P.; Martínez, J. J. y Martínez Tomé, J. (2004): «Productividad y Rentabilidad del agua de riego en la provincia de Alicante». En J. Melgarejo (ed) Repercusiones Socioeconómicas del Plan Hidrológico Nacional en la Provincia de Alicante. Fundación COEPA, Alicante.

MIMAM (2000): Libro Blanco del Agua en España. Ministerio de Medio Ambiente, Madrid.

Murillo, J. M. y Castaño, S. (2003): «Gestión Conjunta de aguas superficiales y subterráneas en un sistema de explotación costero. Aplicación a la Marina Baja de Alicante (España)», en Tecnología de la Intrusión de Agua de Mar en acuíferos costeros: países mediterráneos. IGME, 2003. Madrid.

Ohlson, D. W. (1999): Exploring the application of Adaptive Management and Decision Analysis to Integrated Watershed Management. M.Sc. Thesis, University of British Columbia, 1996. Disponible online: http://scarp.ubc.ca/thesis/ohlson

Prats, D. y Melgarejo, J. (2006): Desalación y reutilización de aguas. Situación en la provincia de Alicante. COEPA, Alicante.

Sahuquillo, A. (1996): «Posibilidades del uso conjunto de aguas superficiales y subterráneas en la planificación hidráulica», en Las aguas subterráneas en las cuencas del Ebro, Júcar e Internas de Cataluña y su papel en la planificación hidro- 
lógica. Asociación Internacional de Hidrogeólogos - Grupo Español. Actas de las Jornadas de Lleida, 1996.

Sánchez, J. R.; Eisenhuth, D.; Bellot, J.; Bonet, A.; Aledo, A.; Peña, J.; Monsalve, J. y TejADA, J.C. (2004): «Los vínculos existentes entre los recursos hídricos, la calidad ecológica y el desarrollo sostenible de una comunidad humana en la Marina Baja: Una perspectiva coevolutiva», en IV Congreso Ibérico sobre Gestión y Planificación del Agua. Tortosa.

Vera, J. F; CASAdo, J. M.; Ramón, A. (2004): «Consideraciones sobre el impacto del Plan Hidrológico Nacional en el sector turístico de la provincia de Alicante», en J. Melgarejo (Ed.) Repercusiones Socioeconómicas del Plan Hidrológico Nacional en la provincia de Alicante. Fundación Coepa, Alicante. 